\title{
The Relation Between Psychiatric Disorders and Substance Abuse in Adolescence and Young Adulthood
}

\author{
Areeg Osama El Shaarawy ${ }^{1 *}$, Nermin Shaker ${ }^{2}$, Eman Ibrahim Abo El Ella ${ }^{2}$ and Menan Abd El Maksoud ${ }^{2}$ \\ ${ }^{1}$ Ain Shams University Hospital, Egypt \\ ${ }^{2}$ Professor of Psychiatry, Ain Shams University Hospital, Egypt \\ *Corresponding Author: Areeg Osama El Shaarawy, Ain Shams University Hospital, Egypt.
}

Received: May 14, 2019; Published: July 09, 2019

DOI: $10.31080 /$ ASNE.2019.02.0076

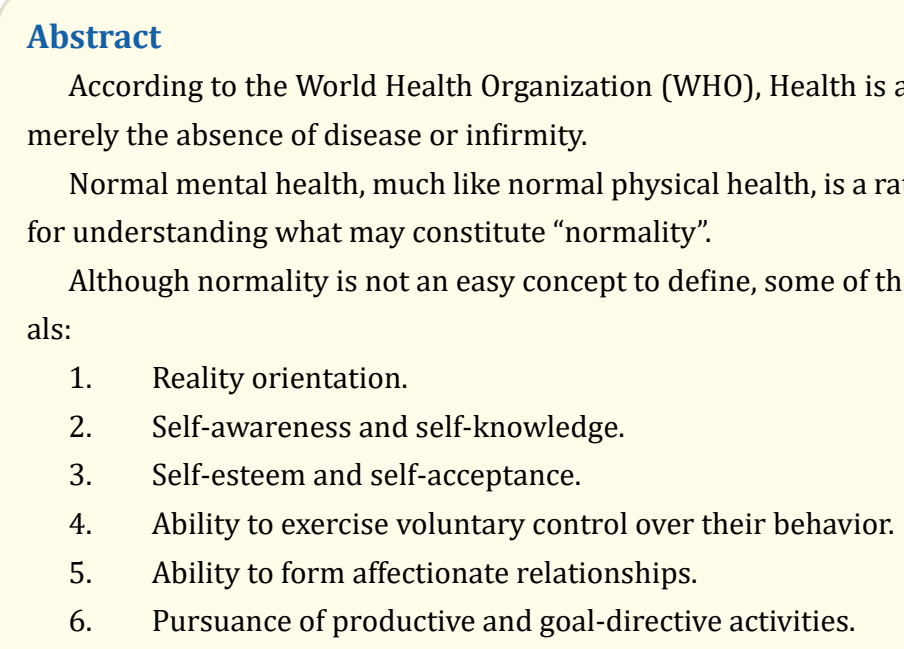

Although it is sometimes assumed that childhood and adolescence are times of carefree bliss, as many as $20 \%$ of children and adolescents have one or more diagnosable mental disorders. Most of these disorders may be viewed as exaggerations or distortions of normal behaviors and emotions.

Keywords: Psychiatric Disorders; Adolescence; Adulthood

\section{Introduction}

According to World Health Organization- Eastern Mediterranean regional office EMRO-technical paper on the addiction and substance use in the Middle Mediterranean Area substance use among youth (15-24 years) is increasing at a rapid rate. Studies have shown decreases in the mean age of onset of drug use [35] in every generation. The reasons behind the increase of prevalence of addiction and substance use in the region are the geographic location, the decrease in the age of beginning of substance use from 14-18 to 11 years and socioeconomic factors: one group affords buying illicit drugs, while the other poor and unemployed group is encouraged to start using substance.
Substance use disorders have a serious impact on adolescents because these disorders have high prevalence rates and frequent associations with psychiatric disorders. Surveys of adolescent behaviors and substance use show that alcohol is the most common substance abused by adolescents. Despite the high rates of current alcohol use and binge drinking among adolescents, current diagnostic criteria are problematic. Adolescents may have a developing problem with substance dependence but not meet the criteria for either substance abuse or dependence. At-risk adolescents, called "diagnostic orphans", may meet only 1 or 2 criteria for alcohol dependence and no abuse criteria and therefore do not receive an alcohol use disorder diagnosis from the Diagnostic and Statistical Manual of Mental Disorders, Fourth Edition, Text Revision (DSM 
IV). Adolescents with substance use disorders tend to have higher rates of comorbid psychiatric disorders and are more likely to report a history of trauma and physical and/or sexual abuse than adolescents without a substance use disorder. In addition, psychiatric disorders in adolescents often predate the substance use disorder. Once the substance use disorder develops, the psychiatric disorder may be further exacerbated [9].

\section{Unmet Need for Mental Health Care is High FIGURE 1 Use of Mental Health Services for Children and Adolescents

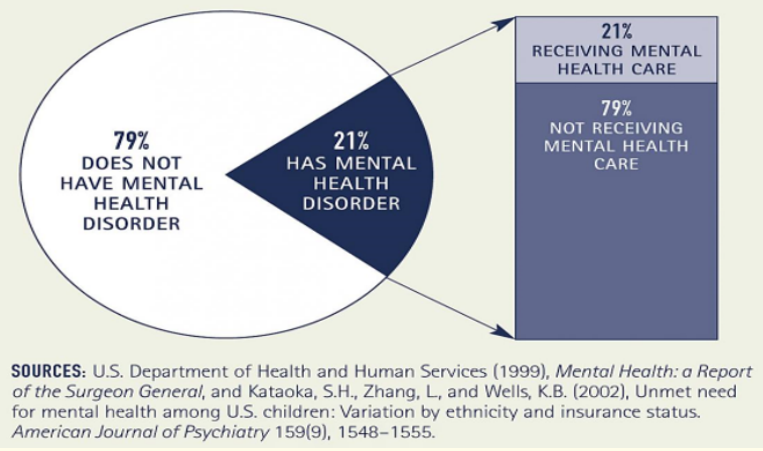

Figure 1: Use of mental health services for children and adolescents.

This figure shows that a very small percentage of children and adolescents with psychiatric disorders actually seek treatment at the psychiatric facilities. This is due to many factors which shall be investigated in this study.

\section{Rationale}

Substance abuse in adolescents is a serious problem which affects a marked percentage of adolescents nowadays. Psychiatric disorders may present as a risk factor for substance abuse. Treatment of these comorbid psychiatric disorders may prevent the persistence of this problem into adulthood.

\section{Hypothesis}

- Psychiatric Disorders precede the Substance Use Disorders.

- Stress is one of the major contributing factors to the develo pment of SUD.

\section{Aim of the Work}

- Investigating the types and rates of occurrence of the psychi atric disorders and psychosocial variables that coexist with drug dependence.
- Assessing the role of stress on substance abuse in adolescents and young adults.

\section{Substance Abuse in Adolescence}

Substance use, misuse, and dependence are amongst the most prevalent causes of adolescent morbidity and mortality in the world, eventhough, there is increased attention to drug demand reduction in recent years. Worldwide, UNODC (United Nations Office on Drugs and Crime) estimates that, in 2009, between 149 and 272 million people, or $3.3 \%$ to $6.1 \%$ of the population aged $15-64$, used illicit substances at least once in the previous year. Almost half that number are estimated to have been current drug users, that is, having used illicit drugs at least once during the past month prior to the date of assessment. Hence the total number of illicit drug users has increased since the late 1990s; however, the prevalence rates have remained largely stable, as has the number of problem drug users, which is estimated at between 1 and 39 million. Approximately 200,000 deaths from drugs were reported in 2012. This figure corresponds to a mortality rate of 40.0 among the population aged 15-64 (United Nations Office on Drugs and Crime. Drug report 2010, 2011).

\section{Definitions}

- $\quad$ Risky use : Risky use of alcohol or other drugs is characterized by consumption amounts that increase the likelihood of health consequences (eg, injury, interpersonal problems, medical consequences).

- $\quad$ Substance use disorder (SUD): The psychiatric diagnoses, substance abuse and substance dependence, in DSM-IV-TR were replaced by one diagnosis, substance use disorder, in DSM-5 [1]. Although the crosswalk between DSM-IV and DSM IV-5 disorders is imprecise, substance dependence is approximately comparable to substance use disorder, moderate to severe subtype, while substance abuse is similar to the mild subtype. DSM-5 criteria for SUD are consistent across substances.

- Physical dependence: A state of adaptation that is manifested by a withdrawal syndrome that can be produced by abrupt cessation of a substance or by tolerance of the substance.

- Addiction : A primary, chronic, neurobiological disease, with genetic, psychosocial, and environmental factors influencing its development and manifestations. Addiction is characterized by behaviors that include impaired control over substance use, compulsive use, continued use despite harm, and craving [47]. 
- Unhealthy alcohol or other drug use: Unhealthy use refers to the spectrum of use that can result in health consequences [47]. As such, it includes risky use, substance use disorder, and use in between - i.e., use that has already resulted in consequences but not yet a diagnosable disorder (often referred to as problem use, misuse, or hazardous use).

\section{Special populations}

Some groups of patients have particular risk factors or may require special approaches to recognizing and treating SUD:

- Adolescents should be advised about the potential dangers of use of any substances, such as alcohol and tobacco, which are legal (though not for purchase by their age group), as well as illegal substances. It may be helpful, when interviewing an adolescent, to begin by asking whether illicit drugs are available at school, whether the patient has close friends who use drugs, and whether the patient has access to drugs.

- $\quad$ Patients with co-occurring psychiatric conditions (including depression, anxiety disorders and some personality disorders) have increased rates of SUDs compared to the general population.

- Pregnant women may not admit substance use because of the guilt they experience about its detrimental effects on their pregnancy, as they also fear legal consequences, including loss of custody of children [49].

- Health care workers may be at an increased risk for addiction, due to high-stress occupations and access to controlled substances.

- Medical patients can become addicted to prescribed medications, including opioids, sedative-hypnotics, and stimulants, which can be obtained from prescribing clinicians or illicitly.

\section{Substance abuse situation in Egypt}

Bureau for International Narcotics and Law Enforcement Affairs, 2014, published a report assessing the drug situation in Egypt emphasizing that Egypt's location makes it a potential transit point for trafficking of heroin and cannabis from major production areas in South East Asia to European markets. Even though Egypt is not a major producer or supplier of narcotics or precursor chemicals, there is significant consumption of hashish and the opioid painkiller tramadol in the country. There have been alarming trends with regards to seizures of cannabis herb (Bango) within Egypt; these include a March 2013 seizure of approximately 27 million tablets of Tramadol at the Port of Alexandria and an August 2013 seizure of 99,000 tablets of tramadol from a vehicle in 6th October City.

In 2011 Egypt's total population was 81.7 million; in rural and lower socioeconomic classes in Cairo, $7 \%$ of the population of whom are 15 years and older were addicts. The study showed that those who used substance at least once were $9.8 \%$ of total, experimental use was $3.1 \%$, regular use $4.8 \%$ and dependence was $1.6 \%$. The most common substances were cannabis and its derivatives $93.5 \%$, alcohol and its derivatives $22.6 \%$, pharmaceutical drugs $11.7 \%$, opiates and its derivatives $7.3 \%$, amphetamines $5.3 \%$ and synthetic drugs $0.31 \%$ (Hamdi., et al. 2011).

Okasha (2011) [35] reported that although cannabis consumption in Egypt is a centuries' long tradition, recent evidence on drug abuse shows new patterns and trends: young people from all socioeconomic strata of society are increasingly involved with both traditional drugs, such as hashish and the new pharmaceutical psychotropic substances that are emerging.

Risk factors for substance abuse in youth

- Age: Alcohol and substance use are highest among the age group 20-45 than the other age groups [19] and [38] found that the age of onset is between 12-16 years. Age specific prevalence tended to double every 5 years. Among the age group below 20, one in every 36 persons had tried an addictive substance at least once, 16 of those who tried illicit drugs will turn into regular use, 4 of regular uses will fall into addiction [11].

- $\quad$ Education and employment: Hamdi et al. (2011) [19] found that there is an inverse relationship between the education level and the substance abuse. As well as that, the addiction was found more amongst those who are manual workers. However, [35] found that $34 \%$ of the university students who had succeeded in their studies and $42 \%$ of those who had failed, used drugs especially cannabis.

- Gender: Addiction is more common in males than females. As well as that, during the past few years alcohol addiction has showed gradual increase [35]. Regarding the one time use of addictive substance; the ratio between male to female reaches up to 13:1. This indicates that although addiction is a much greater problem amongst men, it is also a growing problem amongst women in Egypt. Drug users have been found to be more exposed than non-users to what we call "drug culture"; 
hearing about drugs, seeing drugs, having personal friends who take drugs as well as close relatives who abuse them. When it comes to girls, close relatives have more weight than personal friends as sources of information about drugs [38].

- Marital Status: There is no distinct rule as to whether substance abuse is more common amongst married or single people. In some ways, both have their reasons that linger them extremely vulnerable to addiction. For instance, Mossallami (1988) has portrayed that the reason why some studies found a high percentage of single people amongst drug abusers, is due to the social instability, loneliness and sexual dysfunction that they experience. However, another study conducted by the national research on addiction (NRA) in 1996, has concluded that more married people tend to be attracted by illegal drugs to help alleviate tension or increase sexual activity [43].

- Social Factors: Having a positive history of drug abuse increases the possibility of teens becoming drug abusers themselves [43]. As well as that, several Egyptian researches have concluded that living away from parental supervision and support leads to a higher risk of drug abuse and to an increasing influence of peer pressure (the main reason why teens learn about drugs in the first place). Drug users have reported weak family ties, quarrelsome home atmospheres and persistent exposure to drug-related stimuli. More importantly, the disappearance of the "role model" in the family -whether that may be the "father-figure" or the "mother-figure"- has led to teenagers losing their identity and escaping their troubles via drugs [38].

A study that conducted urine and blood tests on a sample of patients admitted to the hospital estimated that alcohol or drug use was involved in 14 percent of the medical admissions and 26 percent of the psychiatric admissions. Addiction affects adolescents and the elderly, all races, and all socioeconomic strata. Despite the relatively high prevalence of SUD, the disorder frequently goes undetected in clinical care.

Clinicians should evaluate all new patients for unhealthy alcohol use, and other drug use when relevant (eg, high prevalence, consideration of prescribing a potentially addictive medication); drug and alcohol use should also be considered when patients present with new symptoms, recent motor vehicle accidents or physical trauma, mood disorders, weight loss, or ongoing unexplained symptoms.
Types of substances commonly abused by adolescents

\section{Cannabis abuse}

According to the World Health Organization (WHO), 147 million people, or 2.5 percent of the world population, use cannabis (marijuana), making it the world's most widely cultivated, trafficked, and abused illicit substance (WHO, 2014). Use is high in the adolescent age group; as an example, among surveyed adolescents in the United States, approximately 7 percent of 8th graders, 18 percent of 10 th graders, and 23 percent of $12^{\text {th }}$ graders reported cannabis use in the past month.

Several countries, including Canada, Switzerland, and the United States are contemplating or actually liberalizing laws governing cannabis use. At the United States federal level, cannabis products are classified as Schedule 1, i.e, no currently accepted medical use and a high potential for abuse [22]. However, over 20 states have decriminalized medical marijuana or are reviewing legislation to allow low-dose delta- 9 tetrahydrocannabinol (THC) products for specific medicinal indications. In some regions, such as Colorado and Washington, the retail sale and possession of recreational marijuana is legal [26]. Both decriminalization and legalized recreational use have been associated with increased unintentional pediatric ingestions [44]. In regions where medical marijuana is available, diversion of drug from registered users may also encourage adolescent abuse.

In other countries where cannabis can be used legally, rates of usage vary. For example, in the Netherlands, the overall annual prevalence of cannabis usage is 23 percent among young adults compared with 5 percent annual usage reported by people 12 to 64 years of age in Uruguay. Thus, the impact of decriminalization or legalization on the subsequent prevalence of cannabis usage is not easily predicted and varies depending upon the specifics of regulatory enactment.

In today's modern world, substance use is an easy way for adolescents to satisfy the normal developmental need to take risks and seek thrills. Not surprisingly, substance use is common as adolescents get older, and about $70 \%$ of adolescents will try alcohol before high school graduation. However, recurring or ongoing substance use is much less common. Even occasional substance use is risky and should not be trivialized, ignored, or allowed by adults. Parental attitudes and the examples that parents set regarding their own use of alcohol, tobacco, prescription drugs, and other substances are a powerful influence. 


\section{Alcohol abuse}

Globally, alcohol is the substance most often used by adolescents. About $70 \%$ of adolescents report having tried alcohol, although only $55 \%$ say they have ever been drunk. Heavy alcohol use is also common, and nearly $90 \%$ of all alcohol consumed by adolescents occurs during a binge. A binge is generally considered to be consuming more than 4 drinks within 2 hours or less. However, for small people, such as younger girls, as few as 2 drinks may cause enough intoxication to be considered a binge. Binges put adolescents at risk of accidents, injuries, unwanted sexual activity, and other unfortunate situations. For these reasons, adolescents should be discouraged from drinking.

Society and the media portray drinking as acceptable or even fashionable. Despite these influences, parents can make a difference by conveying clear expectations to their adolescent regarding drinking, setting limits consistently, and monitoring. On the other hand, adolescents whose family members drink excessively may think this behavior is acceptable. Some adolescents who try alcohol go on to develop an alcohol use disorder. Risk factors for developing a disorder include starting drinking at a young age and genetics. Adolescents who have a family member with an alcohol use disorder should be made aware of their increased risk

\section{Tramadol abuse}

Natural opiates are acquired by processing the dried "milk" of the opium poppy plant. Synthetic opiates, on the other hand, are formulated in labs to create a product with an identical chemical structure. These drugs--both natural and synthetic forms--compose a group of painkillers called opioids that alleviate the symptoms of discomfort associated with pain.

Tramadol is a synthetic opioid analgesic which has been approved by the United States Food and Drug Administration to treat moderate to severe pain in adults. Analgesics like Tramadol bind to receptors throughout the central nervous and the gastrointestinal systems. The narcotic, also known as a CNS depressant, dulls or eliminates the sensation of pain signaled to the brain.

According to the Drug Enforcement Administration (DEA), Tramadol has more than one name, including its chemical name, 2-[(dimethyl amino) methyl]-1-(3-methoxyphenyl) cyclohexanol, and its trade name, Ultram. The prescribed pain medication should be administered orally in tablet form, dosed between $50 \mathrm{mg}$ and $100 \mathrm{mg}$, at a rate of every 4 to 6 hours, as needed. Dosages should not exceed 400mg in a single day. In 2014, the United States Drug
Enforcement Administration listed Tramadol under the Schedule IV classification for controlled substances because of its abusive potential.

Tramadol is associated with the following behaviors that indicate addiction:

- Development of cravings when not using the drug.

- Development of tolerance effects or requiring more and more of the drug to achieve the same effects.

- Use for nonmedical purposes.

- Inability to control use.

- Continually taking the drug regardless of the harm it causes, physically or psychologically.

- "Drug seeking" behavior such as constantly "losing" prescriptions, arriving at clinics at the end of business hours, refusing examinations, or tampering with medical records or prescriptions.

- $\quad$ "Doctor shopping".

- Failing to perform as expected at work or school due to drug-related impairments

- $\quad$ Neglecting friends and family in order to use or obtain drugs

It is important to note that these behaviors are not exclusive to those with a history of substance abuse; it is possible to develop an addiction to Tramadol despite having no previous addictive relationship with opiates or any other substances. However, according to the US National Library of Medicine National Institutes of Health, a history of drug addiction does increase the likelihood of abuse.

Individuals who take Tramadol for longer periods or in greater dosages than is prescribed by a physician are at risk of dependency. Misuse of this narcotic over a period of time can lead to drug overdose or, even worse, death.

\section{Long-term tramadol abuse side effects}

- Decreased breathing rate.

- Weakened immune system.

- Heightened risk of infectious diseases.

- Constipation.

- Dizziness.

- Headache.

- Nausea

- Vomiting.

- Intense drowsiness

- Collapsed veins or clogged blood vessels.

- Coma. 
The University of Utah Health Library notes that yet another sign of a developing dependency on opioids is the experience of Tramadol addiction withdrawal symptoms after suddenly stopping its use. If Tramadol is discontinued abruptly, a user may experience: insomnia, sweating, anxiety, nausea, diarrhea, muscle pain, pilo-erection, and, occasionally, hallucinations.

While the above-listed symptoms tend to occur in most users who experience Tramadol addiction withdrawal, some users also endure atypical symptoms including unusual sensory phenomena, confusion, de-realization, and delusional behavior, as well as visual, auditory, and tactile hallucinations. These atypical withdrawal symptoms may require intensive medical treatment to overcome.

Comorbidity of substance abuse and other psychiatric disorders in adolescents

Psychopathology coexisting with substance abuse in adolescents is often encountered in a variety of clinical settings. Research findings suggest a major role for substance use in the etiology and prognosis of psychiatric disorders such as affective disorders, conduct disorder and antisocial personality disorder, attention-deficit hyperactivity disorder, and anxiety disorders. Psychiatric disorders also appear to have an important role in the etiology of and vulnerability to substance use problems in adolescents. Although the comorbidity of substance abuse and other psychiatric disorders in adolescents is recognized as an important factor in the treatment of adolescents, further research is needed to establish its prevalence, genetics, and clinical implications [4].

Amongst the most common psychiatric disorders related, in some manner, to substance abuse are affective disorders, antisocial personality disorder, anxiety disorders, and eating disorders. In adolescents, this list expands to include conduct disorder (the childhood-adolescence prodrome of antisocial personality disorder) and attention-deficit hyperactivity disorder.

\section{Affective disorders}

Affective disorders are perhaps the most studied psychiatric problems coexisting with substance abuse. Among the theoretical and empirical relationships between affective disorders and substance abuse are the high prevalence of coexisting affective disorders and substance abuse in cross-sectional studies, affective symptoms or disorder developing as a consequence of substance abuse, affective disorders and substance abuse altering the course of the coexistent disorder, affective disorders as a risk factor for the development of substance abuse, and affective disorders sharing a common origin or being the result of a common vulnerability. The high prevalence of depressive symptoms in adolescent substance abusers is well established. Various studies show high rates of depressive symptoms in alcoholics [45].

[23] interviewed 100 adolescent substance abusers in a drop-in counseling center for young people and found that $16 \%$ showed evidence of double depression (a major depression superimposed on a dysthymic disorder). As well as that, in a study of symptom frequency and severity in depressed adolescents, Ryan et al. reported that excessive use of alcohol was associated with the psychotic subtype, a suicidal plan or attempt, phobia with avoidance, and conduct problems and conduct disorder. The use of other illicit drugs was associated with the psychotic subtype of depression as well as with conduct problems and disorder. This is in addition to evidence of high rates of depression.

\section{Schizophrenia}

Schizophrenia and addiction are both chronic disorders with serious complications, consequences, and costs for individuals and society. Both conditions are associated with poor adherence to treatment and poorer outcomes when the co-occurring disorder is present.

Some of the symptoms of schizophrenia overlap with symptoms of intoxication, chronic use, or withdrawal from alcohol or other drugs. Family history and the temporal relationship of symptoms can help to distinguish patients with a substance use disorder (SUD) alone from co-occurring schizophrenia and SUD.

The lifetime prevalence of the DSM-IV-TR disorders substance abuse and substance dependence amongst patients with schizophrenia has been estimated to range from 47 to 59 percent in the United States (US), compared to 16 percent in the general population [24]. High rates of co-occurrence have also been observed internationally (eg, in Australia, Switzerland, Italy, Germany, England) [6]. Many with these co-occurring disorders used two or more substances.

\section{Prevalence}

Epidemiologic studies have generally shown that the prevalence of substance use disorder (SUD) is elevated in persons with schizophrenia compared with the general population. As examples, in a study of substance use amongst 9142 individuals with severe psychotic disorders, including 5586 subjects with schizophrenia or schizoaffective disorder, the odds of nicotine (smoking), alcohol, marijuana, and other drug use was higher (odds ratios $=3.5$ to 4.6 ) 
in patients with psychosis compared with 10,195 non-psychiatric controls [20]. Rates of substance use varied amongst subgroups based on age, gender, and race or ethnicity. Having a psychotic disorder further increased the odds of substance use in each subgroup. The lifetime prevalence of the DSM-IV-TR disorders substance abuse and substance dependence among patients with schizophrenia has been estimated to range from 47 to 59 percent in the United States (US), compared with 16 percent in the general population [40]. Differences between schizophrenia patients and normal controls in substance use may be diminished when the effects of low socioeconomic status (common among schizophrenia patients) is taken into account. High rates of co-occurrence have also been observed internationally (eg, in Australia, Switzerland, Italy, Germany, England) [6]. Many with these co-occurring disorders used two or more substances.

According to the Epidemiologic Catchment Area study in the US, the substances most commonly used by persons with schizophrenia, ranked by frequency, were [28]:

- $\quad$ Nicotine - 90 percent

- Cannabis -27 percent

- Alcohol-21 percent

- $\quad$ Cocaine - 15 percent

Further information about use of specific substances by schizophrenia patients is described below:

\section{Nicotine}

Nicotine was the most frequently used substance among US persons with schizophrenia over their lifetime in the US. A meta-analysis of 42 studies on tobacco smoking among subjects with schizophrenia found an average prevalence of 61 percent [8]. In contrast to the general US population, tobacco smoking has not declined amongst individuals with schizophrenia in recent decades [20]. Persons with schizophrenia additionally smoke more cigarettes with more numerous and deeper inhalations [50].

\section{Alcohol}

An apparent decline in alcohol use disorders in schizophrenia patients has been associated with the implementation of stricter criteria for the disorder in later editions of DSM through DSM-IVTR [28].

\section{Cannabis}

With this decline, cannabis overtook alcohol as the next most frequently abused substance after nicotine in this population. A meta-analysis of 35 studies involving sixteen countries found a lifetime median of 27 percent for cannabis use in persons with schizophrenia [28]

\section{Stimulants}

A meta-analysis of 64 epidemiologic studies of patients with psychosis found a pooled prevalence rate of 8.9 percent for stimulant use disorder. Estimates of stimulant use disorder varied widely, depending upon the country studied, the clinical setting, the prevalence of co-occurring cannabis use, the rate of affective psychosis, and the use of biological assays to confirm stimulant use. The type of stimulants used reflected the stimulants popular in the general population of the country studied, e.g., cocaine in the US and amphetamines in Australia, leading the authors to suggest that people with psychosis are influenced by the same socioeconomic drivers of drug use and choice as are other members of their communities.

Approximately 15 percent of patients with schizophrenia were found to have co-occurring cocaine use in the 1990s' Epidemiologic Catchment Area study in the US. The more recent Clinical Antipsychotic Trials of Effectiveness study found that of 1432 patients with chronic schizophrenia, 36 percent reported using cocaine in the US (Swartz., et al. 2006). Those with a co-occurring cocaine use disorder had poorer overall functioning compared with patients with a co-occurring SUD with a substance other than cocaine [39].

Opioids

Study of co-occurring schizophrenia and opioid abuse/misuse has been limited, with findings of generally low prevalence rates:

- A retrospective study of medical records of 146 Finnish patients with schizophrenia found a prevalence of opioid use of 4.1 percent.

- In a study of 219 opioid-dependent patients in Germany, only two (1 percent) met criteria for schizophrenia [27].

- A study of 75 opioid-dependent patients in New York City found that eight (11 percent) reported symptoms consistent with schizophrenia [30].

Risk factors - Studies suggest that patients with schizophrenia and one or more of the following risk factors are more likely to have a co-occurring substance use disorder (SUD) [41]:

- Younger.

- $\quad$ Male.

- Homeless. 
- Incarcerated.

- Urban.

Frequent cannabis use, especially at an early age, seems to be an important risk factor associated with development of schizophrenia [10].

\section{Pathogenesis}

Etiologic theories - Causes of the co-morbidity between schizophrenia and substance use disorder (SUD) are not known. Etiological theories can be categorized into four groups: common factors, secondary SUD, secondary mental disorder, and bidirectional models. These models vary in their extent of supporting evidence and are not mutually exclusive. In any individual case, more than one mechanism may contribute to comorbidity.

\section{Common factors}

This model hypothesizes that the comorbidity results from risk factors common to both disorders. A shared genetic vulnerability has been proposed to underlie dopaminergic and glutamatergic dys-regulation in schizophrenia and substance abuse (Ng., et al. 2013). The association between schizophrenia and cannabis has been proposed to be due to a shared genetic etiology (Power., et al. 2014). Impaired myelin development has been studied as a possible precursor (Feng., et al. 2008). In addition, early life environmental insults could cause developmental dysfunction in common neural circuitry pathways, eg, the meso-cortical limbic dopamine system, underlying both disorders (Ng., et al. 2013).

Any theory of causality for comorbidity must take into account and adjust for the confounding or contributing effect of common demographic and socioeconomic risk factors (the cumulative risk hypothesis) (Ng., et al. 2013). There is ample evidence that schizophrenia is diagnosed at a higher rate among disadvantaged, minority, and lower socioeconomic groups (Fryers., et al. 2005) which are also prone to higher rates of substance use and greater resistance to treatments for addiction (Brown., et al. 2014). It may be misleading to compare patients with schizophrenia with the general population without controlling for demographic and socioeconomic factors. People with schizophrenia have generally been found to use the substances that are readily available and affordable in their communities (Sara., et al. 2015).

\section{Secondary mental disorder}

This model posits that substance use disorder precipitates mental disorders in genetically predisposed individuals (the diathesis-stress or two-hit hypothesis) (Ng., et al. 2013). Retrospective studies report mixed results on the temporal relationship between the disorders (Westermeyer., et al. 2006). The strongest evidence for this model is from findings of a dose-related association between cannabis use and the subsequent onset of schizophrenia (Ng., et al. 2013). The significance of these findings remains controversial and a causative role has not been proven. The vast majority of cannabis users do not develop schizophrenia, and not everyone diagnosed with schizophrenia has been exposed to cannabis (Wilkinson., et al. 2014).

\section{Secondary substance use}

This model is also known as the "self-medication hypothesis", proposing that individuals with schizophrenia use substances to reduce their symptoms or to counteract secondary side effects of antipsychotic drug treatment (Samaha., et al. 2014). As an example, patients with schizophrenia may use stimulants to reverse negative symptoms or depressed mood. Accumulating data support the idea that nicotine derived from smoking tobacco affects several neurotransmitter systems, including dopamine, glutamate, and gamma-aminobutyric acid, and that certain neurocognitive deficits in schizophrenia associated with these neurotransmitters (eg, reaction time, spatial working memory, sustained attention) are improved after nicotine administration (Mackowick., et al. 2014). Smoking tobacco (not related to nicotine intake per se) has been found to lower plasma levels of antipsychotic drugs (Lohr., et al. 1992). Most studies, however, do not support this hypothesis. Substances used by individuals vary and appear to be motivated by several factors in addition to the individual's symptoms.

\section{Bidirectional}

This model suggests that the presence of either a mental disorder or SUD can contribute to the development of the other in a mutually reinforcing manner over time. This model is largely theoretical and lacks supporting evidence from research.

\section{Neurobiology}

The dopaminergic and glutamatergic systems are involved in the etiology of schizophrenia. A deficiency is postulated in the dopamine-mediated mesocorticolimbic brain reward circuits in people with schizophrenia. Substances of abuse are believed to enhance this deficit. Drugs such as nicotine, alcohol, and cocaine may reinforce brain reward pathways by increasing levels of dopamine in the nucleus accumbens of the limbic system. A specific example is cocaine, which blocks the dopamine transporter from reuptake of dopamine, thereby increasing the amount of dopamine in the synapse available to bind to and activate post-synaptic dopamine receptors (Chambers., et al. 2001). Another example is nicotine, which is used by a high proportion of individuals with schizophre- 
nia, and which affects the dopamine reward pathway by binding to nicotinic acetylcholine receptors in the midbrain during smoking (Mobascher., et al. 2008). These neurons project from the ventral tegmental area to the nucleus accumbens where dopamine release leads to experiences of reward, promoting impulsive, addictive behavior (Chambers., et al. 2001).

Deficiencies in dopaminergic neurotransmission in the mesolimbic regions and anterior striatum may result in cravings, leading schizophrenia patients to be vulnerable to addiction. Substance use disorder may modify signal detection, improving negative effects of schizophrenia overall, even in the absence of antipsychotic medications (Chambers., et al. 2001).

Several hypotheses and associated research address specific substances:

Nicotine

Among the cognitive deficits in schizophrenia is visual-spatial memory. Hypofunction of cortical dopamine in the hippocampus of schizophrenia results in impaired performance in visual-spatial working memory. Smoking tobacco, acting on the prefrontal cortex via activation by nicotine of dopamine release, leads to transient improvements in tasks and attention (Adler., et al. 1993).

Data from animal models are consistent with the self-medication hypothesis (ie, that schizophrenia patients smoke tobacco in part for the beneficial effects of nicotine on cognition. These studies found that agonist activity of nicotinic agents at the alpha-7 acetylcholine receptor in the hippocampus and anterior cingulate corrects the visual-spatial memory impairment, sensorimotor gating abnormalities, social abnormalities, and changes in striatal dopamine release that have been demonstrated in genetic and transgenic rodent models of schizophrenia (Mackowick., et al. 2014).

\section{Cannabis}

Cannabinoids have been shown in animal models to modulate release of neurotransmitters implicated in psychosis, including dopamine and gamma-aminobutyric acid by activating cannabinoid-1 receptors (CB1) (Radhakrishnan., et al. 2014). Preclinical evidence suggests that CB1-mediated increases in mesolimbic dopaminergic activity may explain the positive psychotic symptoms induced by tetrahydrocannabinol. Systemic administration of cannabinoids in the rat has been reported to increase prefrontal cortical dopamine release or turnover (Chen., et al. 1990) and could account for the ability of cannabinoids to produce acute deficits in prefrontal cortex related cognitive functions, such as working memory and attention (Radhakrishnan., et al. 2014). Cannabinoid and dopami- ne receptor interactions in the prefrontal cortex, ventral tegmental area, and amygdala are thought to be related to the emotional associative learning difficulties in both SUD and schizophrenia (Laviolette., et al. 2006). Cannabinoids could induce psychosis and cognitive impairment through actions on gamma-aminobutyric acid-ergic systems.

The link between cannabis and schizophrenia may be moderated by age at onset of cannabis use, childhood abuse, and genetic vulnerability (Wilkinson., et al. 2014). Although effects on neurotransmitter systems may account for some of the ability of cannabinoids to cause positive, negative, and cognitive symptoms, the mechanism by which exposure to cannabinoids might represent a risk factor associated with the development of schizophrenia remains unclear and controversial (Radhakrishnan., et al. 2014).

The endocannabinoid system is critical to a number of neurodevelopmental processes that include axon elongation, neurogenesis, neural maturation, neural specification, glia formation, and neuronal migration (Wilkinson., et al. 2014). These processes may be relevant to the neurodevelopmental hypothesis of schizophrenia. Perturbations of the endocannabinoid system in the rapidly changing brain, as is the case in adolescence, may have far reaching consequences.

Cannabis use during adolescence may disrupt neuromodulatory influences of endocannabinoids in individuals with specific CNR1 genetic polymorphisms (Ho., et al. 2011). This could contribute to smaller fronto-temporal white matter volumes and cognitive impairment, which could in turn increase schizophrenia risk. Subsequent assessment of the influence of another cannabinoid-related gene, mitogen-activated protein kinase 14 (MAPK14), suggested that MAPK14-CNR1 gene-gene interactions may mediate brain morphometric features in schizophrenia patients with heavy marijuana use (Onwuameze., et al. 2013).

\section{Opioids}

Since N-methyl-D-aspartate (NMDA) receptors play important roles in the pathophysiology of substance misuse, rare variants in the NMDA-related genes have been hypothesized to exert effects on the risk for substance misuse. Regions of genes involved in the NMDA system were sequenced in subjects with co-occurring DSMIV alcohol dependence, cocaine dependence, and opioid dependence, and healthy controls (Xie., et al. 2014). Eleven rare variants were successfully genotyped, and a statistically significant association of these 11 rare variants with opioid dependence in African Americans was identified. Results from the gene-based association 
tests showed that the association signal derived primarily from disrupted in schizophrenia 1 (DISC1) and GRIN2B. Since DISC1 is a well-validated schizophrenia risk gene, this represents the first demonstration that rare variants affect the risk of opiate misuse and the first demonstration of biological convergence of schizophrenia and opiate misuse.

\section{Antisocial personality disorder}

Antisocial personality disorder (ASPD) is defined as a pattern of socially irresponsible, exploitative, and guiltless behavior that begins in childhood or early adolescence and is manifested by disturbances in many areas of life (North., et al. 2010). It is usually a lifelong disorder that begins in childhood and is fully manifest by the late 20 s or early 30 s (Robins., et al. 1991).

Typical behaviors include criminality and failure to conform to the law, failure to sustain consistent employment, manipulation of others for personal gain, and failure to develop stable interpersonal relationships. Other features of ASPD include lacking empathy for others, rarely experiencing remorse, and failing to learn from the negative results of one's experiences (American Psychiatric Association, 2013).

Persons with ASPD have high rates of other psychiatric diagnoses, including substance misuse, mood and anxiety disorders, attention deficit hyperactivity disorder (ADHD), learning disabilities, pathological gambling, and other Axis II disorders (eg, borderline personality disorder) (Dinwiddie., et al. 1993).

\section{Anxiety disorders}

Substance use disorders (SUDs) have been found to co-occur at an increased rate in posttraumatic stress disorder (PTSD), generalized anxiety disorder (GAD), panic disorder, and social anxiety disorder (SAD). In most instances, the anxiety disorder onset precedes that of the SUD(s). Obsessive-compulsive disorder (OCD) and SUDs have not been found to be strongly associated. Preclinical studies have demonstrated that SUDs and anxiety-related disorders share common neurobiological substrates that include disruptions within the hypothalamic-pituitary-adrenal (HPA) axis and noradrenergic systems (Sinha, 2001).

Clinical observation during a period of prolonged abstinence from substances can distinguish a transient, substance-induced state from a true anxiety disorder. The duration of abstinence necessary for accurate diagnosis varies depending on the substance (Grant., et al. 2004).
Tips for distinguishing anxiety-related disorders without Substance Abuse from the effects of substance intoxication or withdrawal as they differ by disorder

- Most of the symptoms of generalized anxiety disorder can be mimicked by substance use. Assessment should be delayed until symptoms of intoxication or withdrawal have resolved.

- In contrast with obsessive-compulsive disorder, obsessive thinking and compulsive behaviors that occur secondary to a SUD center on the substances used (Modell., et al. 1992).

- Substances, stimulants in particular, can induce panic attacks. In contrast to panic experienced in the context of SUDs, attacks characteristic of panic disorder occur unexpectedly, and patients experience persistent worry about having another attack (Cosci., et al. 2007).

- Hyperarousal symptoms of posttraumatic stress disorder (eg, irritability, sleep impairment, difficulty concentrating, and exaggerated startle response) can be exacerbated by the use of, or withdrawal from, alcohol and drugs.

- The primary feature of social anxiety disorder (SAD), fear of public scrutiny, is not typically mimicked by substance use, intoxication, or withdrawal. Symptoms of SAD that present only in the context of intoxication or withdrawal are not sufficient to meet criteria for a diagnosis of SAD (American Psychiatric Association, 2013).

Prevalence of anxiety disorders comorbid with substance abuse:

- $\quad$ Post-traumatic stress disorder - PTSD, which has an estimated lifetime prevalence of 6.4 to 7.8 percent (Pietrzak., et al. 2011) in US general population, has been shown to commonly co-occur with SUDs.

- The lifetime prevalence of SUDs in persons with non-military PTSD has been reported to range from 21.6 to 43 percent, compared with a range of 8.1 to 24.7 percent in individuals without PTSD (Kessler., et al. 1994).

- A study of 2633 individuals in the general US adult population found that cocaine and opiate users had the highest rates of trauma exposure and PTSD (Cottler., et al. 1992).

- Compared with the general population, military personnel are at increased risk of both PTSD and SUDs (Hoge., et al. 2006). 


\section{Generalized anxiety disorder}

GAD has a lifetime prevalence in the general population of 5.7 percent (Kessler., et al. 2005). The likelihood of having GAD has been strongly associated with the presence of alcohol or drug use disorders in data from the National Epidemiologic Survey on Alcohol and Related Conditions (NESARC), which is based on a nationally representative sample in the US (Grant., et al. 2005).

Across several studies, the prevalence of GAD among patients with a DSM-IV alcohol use disorder ranged from 8.3 to 52.6 percent (Kushner., et al. 1990). Data from the National Comorbidity Study (NCS), a nationally representative sample of US adults, found an association between lifetime GAD and lifetime use of stimulants (odds ratio 2.07), cocaine (odds ratio 2.39), hallucinogens (odds ratio 5.09), and heroin (odds ratio 4.27) (Sareen., et al. 2006).

\section{Panic disorder}

Data from the Epidemiological Catchment Area (ECA) study in five US cities found a lifetime prevalence of panic disorder among adults of 1.5 percent (Regier., et al. 1990). Thirty six percent of patients with panic disorder were additionally diagnosed with an SUD.

Data from four large epidemiological surveys found that the estimated lifetime risk of panic disorder in individuals with DSMIV diagnoses of alcohol abuse or dependence ranged from 0.97 to 3.82 percent, compared to individuals without an SUD (Swendsen., et al. 1998). A study of 1071 subjects participating in the National Household Survey on Drug Abuse in the US estimated that cocaine use was associated with a 3.3-fold excess occurrence of panic attacks (O'Brien., et al. 2009). The lifetime prevalence of panic disorder with and without agoraphobia among patients with an opiate use disorder was 5 percent and 14 percent, respectively (Conway., et al. 2006). A prospective study of 2548 young adults found that panic disorder was a significant predictor of hazardous alcohol use and the persistence of alcohol use disorder (Zimmerman., et al. 2003). The presence of a lifetime diagnosis of drug use disorder was associated with panic disorder (Grant., et al. 2016).

\section{Social anxiety disorder}

Two studies of nationally representative samples in the US estimated the lifetime prevalence of SAD to range from 5.0 to 13.3 percent and the 12-month prevalence to range from 2.8 to 7.9 percent. Alcohol use disorders in individuals with SAD were common, for example, the National Epidemiologic Survey on Alcohol and Related Conditions (NESARC) found a 48 percent lifetime prevalence (Grant., et al. 2005). A study demonstrated modestly increased associations between lifetime SAD and lifetime stimulant, cocaine, hallucinogen, and heroin use (odds ratios 1.86, 1.45, 2.3, and 1.6 respectively) (Sareen., et al. 2006). A strong association has been observed between SAD and marijuana use. The NCS found that individuals with SAD are seven times more likely to have a DSM-IV diagnosis of marijuana dependence than individuals without SAD (Agosti., et al. 2002).

Individuals with SAD are highly vulnerable to substance use disorders (Sareen., et al. 2006). Research shows that socially phobic individuals are two to three times more likely than individuals without SAD to develop an alcohol use disorder (Kushner., et al. 1990). The onset of SAD typically precedes the development of the substance use disorder (Carrigan., et al. 2003), and up to 16.4 percent of socially phobic individuals endorse self-medicating anxiety symptoms with alcohol and drugs (Bolton., et al. 2006). A prospective study of 627 individuals found that SAD was associated with the subsequent onset of alcohol use disorder; PTSD was associated with a subsequent onset of a substance use disorder (Wolitzky-Taylor., et al. 2012).

\section{Obsessive-compulsive disorder}

Unlike other anxiety disorders, individuals with OCD do not appear to have a higher rate of co-occurring SUDs than the general population. A large epidemiological study of six geographic areas in the US found no difference between rates of OCD among individuals with a DSM-IV diagnosis of alcohol dependence compared to a control group without alcohol dependence (Schuckit., et al. 1997). Two studies of patients receiving psychiatric treatment in the US found that only 1.3 to 4.0 percent of patients with OCD met criteria for a lifetime substance use disorder (Sbrana., et al. 2005).

Subjects and Methods

Study design

Cross-sectional, comparative study.

\section{Study site and duration}

- The outpatient clinics (OPC) and the inpatient ward of the Institute of Psychiatry, Ain Shams University Hospitals.

- Duration: 12 months; from August 2014 until July 2015.

- The institute of Psychiatry is located in Eastern Cairo and serves as a catchment area of about the third of Greater Cairo. It serves both urban and rural areas, including areas around Greater Cairo as well. 
Subjects

The sample consisted of 70 adolescents and young adults with substance abuse (cases).

The controls were 35 children and adolescents not taking any type of substance.

\section{Subjects Selection}

Inclusion criteria for the cases

- $\quad$ Age: 15-21 years of age.

- $\quad$ Substance Use Disorder patients.

Exclusion criteria for the cases

- Patient in a state of intoxication or unconsciousness.

- $\quad$ Presence of a chronic medical disorder.

- $\quad$ Limited mental competency.

- Inability to provide written consent.

Inclusion criteria for the controls:

- Matching in age, gender and social status to the cases.

- $\quad$ Not abusing any type of substance.

Exclusion criteria for the controls

- $\quad$ Presence of any form of substance abuse.

- Presence of serious medical conditions.

- Inability to provide written consent.

- $\quad$ Limited mental competency.

\section{Methods}

- Procédures

- Approval and ethical consideration of all procedures were reviewed and approved by the ethical committee of Ain Shams University.

- Any patients within our selected age group who attended the Substance Use Disorder clinic at Ain Shams University Hospitals were asked if they wanted to participate in our study. They were fully informed about the nature of the research and the confidentiality of obtained information.

- It was stated that the participation in the study is voluntary and the participants have the freedom to withdraw at any time.

- If they agreed, then they had to give a written consent.

- Complete physical and psychiatric examination was done.

- Patients below 18 years of age were assessed by the Mini International Neuropsychiatric Interview for Children and Adolescents for diagnosing psychiatric comorbidity.
- $\quad$ On the other hand, patients above 18 years of age, were assessed by the Structured Clinical Interview for DSM-IV.

- Stressful life events were assessed by Social Readjustment Rating Scale for the Young.

Tools

Mini International Neuropsychiatric Interview for Children and Adolescent (MINI-KID) (Sheehan., et al. 1990)

The MINI-KID is a structured clinical diagnostic interview designed to assess the presence of current DSM-IV and ICD-10 psychiatric disorders in children and adolescents aged 6-17 in a way that is comprehensive and concise. The interview was administered to adolescents without a parent present. The MINI-KID follows the structure and format of the adult version of the interview (MINI). Like the MINI, the MINI-KID is also organized in diagnostic section/ modules. Using branching tree logic, the instrument asks 2-4 screening questions for each disorder. Additional symptom questions within each disorder section were only asked if the screen questions were positively endorsed. All questions were in the binary "yes/no" format. It took approximately half an hour to administer, the Arabic version was developed by (Ghanem., et al. 2000).

Structured Clinical Interview for DSM-IV Axis I Disorder (SCID-I) (First., et al. 1995)

It is a clinician administered semi-structured interview for use with psychiatric patients. It provides broad coverage of psychiatric axis I diagnosis according to DSM IV and consists of 9 diagnostic models (mood episode, psychotic symptom, psychotic disorder differential, mood disorder differential, substance use, anxiety, somatoform disorder, eating disorder and adjustment disorder). It is considered the standardized interview to verify diagnosis in clinical trials and is extensively used in other forms of psychiatric research [14]. Arabic version.

Social Readjustment Rating Scale for young

(SRRS-Y) (Holmes., et al. 1967)

The 35 items of social Readjustment Rating Scale for young (SRRS-Y) measure the social life events and transitions that required change upon their occurrence in the past 12 months. Total score is related to the risk of occurrence of mental health problems. Arabic version was used in this study [17].

Fahmy and Sherbini's Social Classification Scale (Appendix 2):

It was used to determine the social class of patients. The socioeconomic status scale has 7 domains. On the basis of patients' education, employment and income and on a crowding and sanitation 
index, to be used as belonging to a high score (25-30), middle score (20-25), low social class (15-20) and very low social class (score 14 or lower) (Fahmy and El Sherbini, 1988). An updated version was used as validated by A. El- Gilany, 2012.

\section{Statistical analysis}

The collected data were coded, tabulated, and statistically analyzed using SPSS program (Statistical Package for Social Sciences) software version 18.0.

\section{Descriptive statistics}

Descriptive statistics were done for quantitative data as mean \pm SD (standard deviation) and minimum and maximum of the range as well as median and $1^{\text {st }}$ and $3^{\text {rd }}$ inter-quartile range, while they were done for qualitative data as number and Frequency and percentage of non-numerical data.

\section{Inferential analyses}

They were done for independent qualitative variables using Fisher's Exact test, Chi test, student test and Anova.

The level of significance was taken at $\mathrm{P}$ value $<0.050$ is significant, otherwise is non-significant. The p-value is a statistical measure for the probability that the results observed in a study could have occurred by chance.

\section{Results}

\begin{tabular}{|c|c|c|c|c|}
\hline \multicolumn{2}{|c|}{ Variables } & $\begin{array}{c}\text { Case } \\
(N=70)\end{array}$ & Control & $\mathbf{P}$ \\
\hline \multirow{2}{*}{$\begin{array}{l}\text { Age } \\
\text { (years) }\end{array}$} & Mean \pm SD & $18.6 \pm 2.3$ & $18.5 \pm 2.1$ & \multirow[t]{2}{*}{${ }^{\wedge} 0.830$} \\
\hline & Range & $15.0-21.0$ & $15.0-21.0$ & \\
\hline $\begin{array}{l}\text { Sex }(n, \\
\%)\end{array}$ & Male & $\begin{array}{c}70 \\
(100.0 \%)\end{array}$ & $\begin{array}{c}35 \\
(100.0 \%)\end{array}$ & \#1.000 \\
\hline \multirow{3}{*}{$\begin{array}{l}\text { Educa- } \\
\text { tion } \\
(\mathrm{n}, \%)\end{array}$} & $\begin{array}{l}\text { Illiterate/ } \\
\text { Low }\end{array}$ & $24(34.3 \%)$ & 7 (20.0\%) & \multirow[t]{3}{*}{ \#0.318 } \\
\hline & Moderate & $23(32.9 \%)$ & $14(40.0 \%)$ & \\
\hline & High & $23(32.9 \%)$ & $14(40.0 \%)$ & \\
\hline \multirow{2}{*}{$\begin{array}{l}\text { Employ- } \\
\text { ment } \\
(n, \%)\end{array}$} & Working & 48 (68.6\%) & 18 (51.4\%) & \multirow[t]{2}{*}{$\# 0.087$} \\
\hline & $\begin{array}{l}\text { Not work- } \\
\text { ing }\end{array}$ & 22 (31.4\%) & 17 (48.6\%) & \\
\hline \multirow[t]{2}{*}{$\begin{array}{l}\text { Marital } \\
(n, \%)\end{array}$} & Single & $68(97.1 \%)$ & $\begin{array}{c}35 \\
(100.0 \%)\end{array}$ & \multirow[t]{2}{*}{ \#0.313 } \\
\hline & Married & $2(2.9 \%)$ & $0(0.0 \%)$ & \\
\hline \multirow{3}{*}{$\begin{array}{l}\text { Social } \\
\text { class }\end{array}$} & Middle & $7(10.0 \%)$ & $4(11.4 \%)$ & \multirow[t]{3}{*}{$\# 0.664$} \\
\hline & low & $5(7.1 \%)$ & $1(2.9 \%)$ & \\
\hline & Very low & 58 (82.9\%) & 30 (85.7\%) & \\
\hline
\end{tabular}

Table 1: Comparison between case and control groups regarding demographic characteristics.

${ }^{\wedge}$ Independent t-test, \#Chi square test, *Significant
The above table shows that the age group in this study was from 15 until 21 years of age. The average age of both the control and the case groups is 18 years of age. The majority of the patients in this sample were single. Family history of substance abuse and psychiatric illness were significantly more among case group than among control group.

\begin{tabular}{|l|l|c|c|c|}
\hline \multicolumn{2}{|c|}{ Variables } & \multicolumn{1}{c|}{$\begin{array}{c}\text { Case } \\
\text { (N=70) }\end{array}$} & $\begin{array}{c}\text { Control } \\
\text { (N=35) }\end{array}$ & P \\
\hline Smoking, (n, \%) & $61(87.1 \%)$ & $10(28.6 \%)$ & $\#<0.001^{*}$ \\
\hline $\begin{array}{l}\text { Duration } \\
\text { (Months) } \\
\text { (smokers } \\
\text { only) }\end{array}$ & Mean \pm SD & $25.4 \pm 16.4$ & $10.7 \pm 5.4$ & $\wedge$ \\
\cline { 2 - 4 } & Range & $5.0-72.0$ & $6.0-24.0$ & \multirow{2}{*}{$<0.001^{*}$} \\
\hline $\begin{array}{l}\text { Cigarettes/ } \\
\text { day } \\
\text { (smokers } \\
\text { only) }\end{array}$ & Mean \pm SD & $17.6 \pm 8.9$ & $15.5 \pm 6.9$ & $\wedge$ \\
\cline { 2 - 4 } & Range & $5.0-40.0$ & $10.0-30.0$ & 0.474 \\
\hline $\begin{array}{l}\text { History of medical } \\
\text { condition }\end{array}$ & $6(8.6 \%)$ & $1(2.9 \%)$ & $\#$ \\
\hline $\begin{array}{l}\text { Family history of } \\
\text { substance abuse, (n, \%) }\end{array}$ & $33(47.1 \%)$ & $0(0.0 \%)$ & $\#$ \\
\hline $\begin{array}{l}\text { Family history of } \\
\text { psychiatric illness, } \\
\text { (n, \%) }\end{array}$ & $23(32.9 \%)$ & $0(0.0 \%)$ & $\#$ \\
\hline
\end{tabular}

Table 2: Comparison between case and control groups regarding Family history of substance abuse \& psychiatric illness and smoking.

${ }^{\wedge}$ Independent t-test, \#Chi square test, *Significant

Smoking and its duration were significantly higher among case group than among control group.

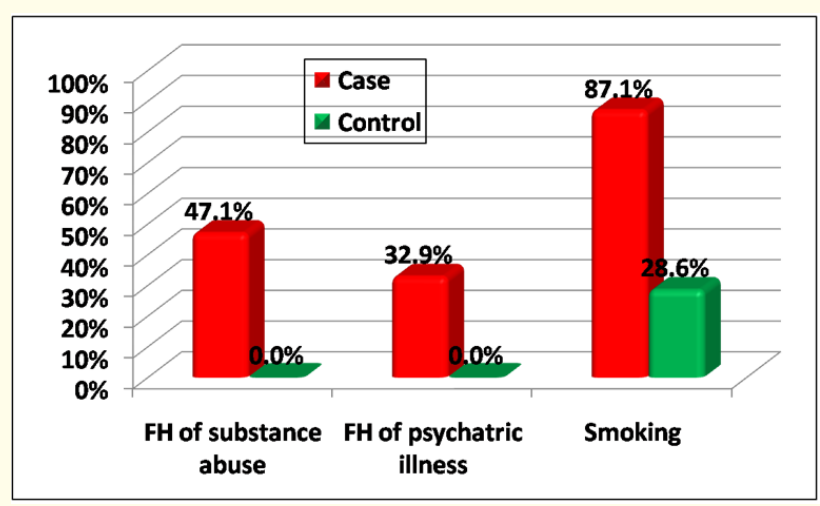

Figure 2: Comparison between case and control groups regarding Family history of substance abuse\& psychiatric illness and smoking. 
The Relation Between Psychiatric Disorders and Substance Abuse in Adolescence and Young Adulthood

\begin{tabular}{|c|c|c|c|}
\hline \multicolumn{2}{|c|}{ Variables } & $\mathbf{N}$ & $\%$ \\
\hline \multicolumn{2}{|l|}{ Hashish } & 51 & 72.9 \\
\hline \multicolumn{2}{|l|}{ Tramadol } & 23 & 32.9 \\
\hline \multicolumn{2}{|l|}{ Alcohol } & 8 & 11.4 \\
\hline \multicolumn{2}{|l|}{ Combination } & 12 & 17.1 \\
\hline \multirow{6}{*}{$\begin{array}{l}\text { Material } \\
\text { combinations }\end{array}$} & Hashish only & 40 & 57.1 \\
\hline & Tramadol only & 14 & 20.0 \\
\hline & Alcohol only & 4 & 5.7 \\
\hline & Hashish and Tramadol & 8 & 11.4 \\
\hline & Hashish and Alcohol & 3 & 4.3 \\
\hline & Tramadol and Alcohol & 1 & 1.4 \\
\hline & & Mean \pm SD & Range \\
\hline \multicolumn{2}{|c|}{ Substance Use duration (months) } & $18.4 \pm 12.7$ & $2.0-60.0$ \\
\hline \multicolumn{2}{|c|}{ Hashish usual dose per day } & $2.3 \pm 1.1$ & $1.0-5.0$ \\
\hline \multicolumn{2}{|c|}{ Hashish maximum dose per day } & $6.2 \pm 3.1$ & $2.0-20.0$ \\
\hline \multicolumn{2}{|c|}{ Tramadol usual dose per day } & $2.7 \pm 1.3$ & $1.0-5.0$ \\
\hline \multicolumn{2}{|c|}{ Tramadol maximum dose per day } & $6.2 \pm 2.6$ & $2.0-10.0$ \\
\hline \multicolumn{2}{|c|}{ Alcohol usual dose per day } & $1.9 \pm 1.1$ & $1.0-4.0$ \\
\hline \multicolumn{2}{|c|}{ Alcohol maximum dose per day } & $5.8 \pm 2.8$ & $2.0-10.0$ \\
\hline
\end{tabular}

\begin{tabular}{|c|c|c|c|c|}
\hline \multicolumn{2}{|c|}{ Variables } & $\begin{array}{c}\text { Case } \\
(\mathrm{N}=70)\end{array}$ & $\begin{array}{l}\text { Control } \\
(\mathrm{N}=35)\end{array}$ & $\mathbf{P}$ \\
\hline \multirow{2}{*}{$\begin{array}{l}\text { Presence of } \\
\text { Psychiatric } \\
\text { illness }\end{array}$} & Yes & $55(78.6 \%)$ & $5(14.3 \%)$ & \multirow{2}{*}{$\begin{array}{c}\# \\
<0.001^{*}\end{array}$} \\
\hline & No & $15(21.4 \%)$ & $30(85.7 \%)$ & \\
\hline \multirow{2}{*}{$\begin{array}{l}\text { Stress } \\
\text { score }\end{array}$} & Mean \pm SD & $277.0 \pm 79.0$ & $200.3 \pm 70.7$ & \multirow{2}{*}{$\begin{array}{c}\wedge \\
<0.001^{*}\end{array}$} \\
\hline & Range & $76.0-462.0$ & $100.0-350.0$ & \\
\hline
\end{tabular}

Table 3: Substance abuse among case group.

Smoking and its duration were significantly higher among case group than among control group.

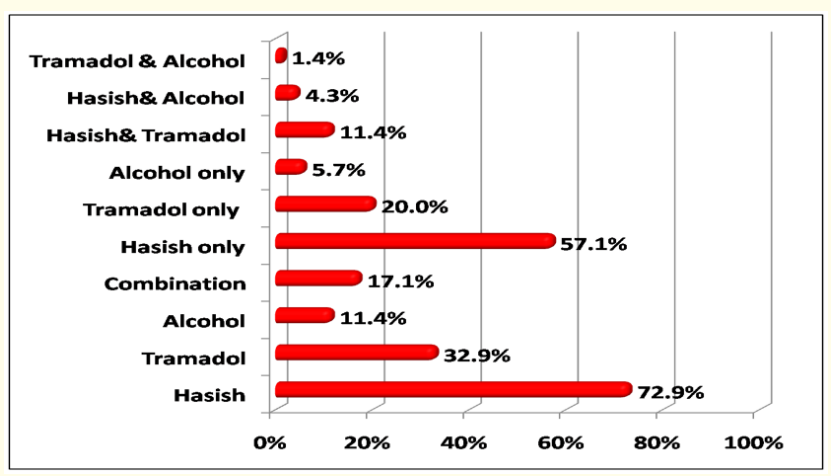

Figure 3: Substance abuse among case group.

Psychiatric illness and stress scores were significantly higher among case group than among control group.

ADHD and bipolar were the significantly more frequent psychiatric illnesses among case group. Majority of cases had psychiatric illness before addiction.
Table 4: Comparison between case and control groups regarding psychiatric condition.

${ }^{\wedge}$ Independent t-test, \#Chi square test, *Significant

$$
\text { ^Independent t-test, \#Chi square test, *Significant }
$$

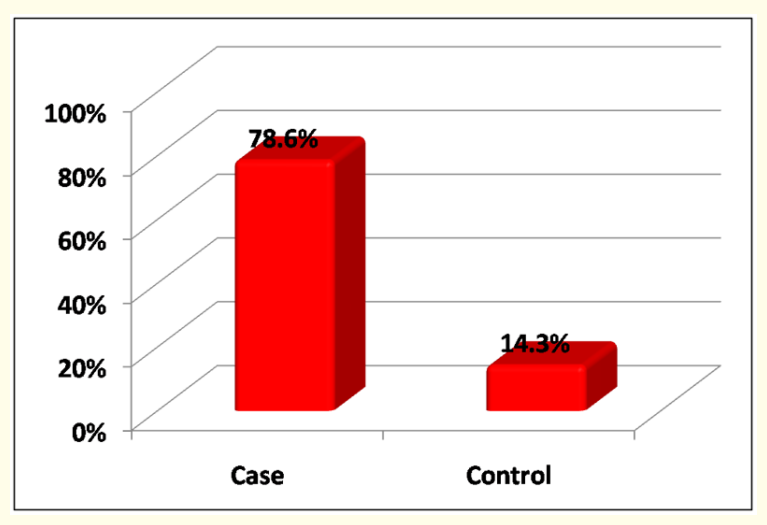

Figure 4: Comparison between case and control groups regarding psychiatric illness.

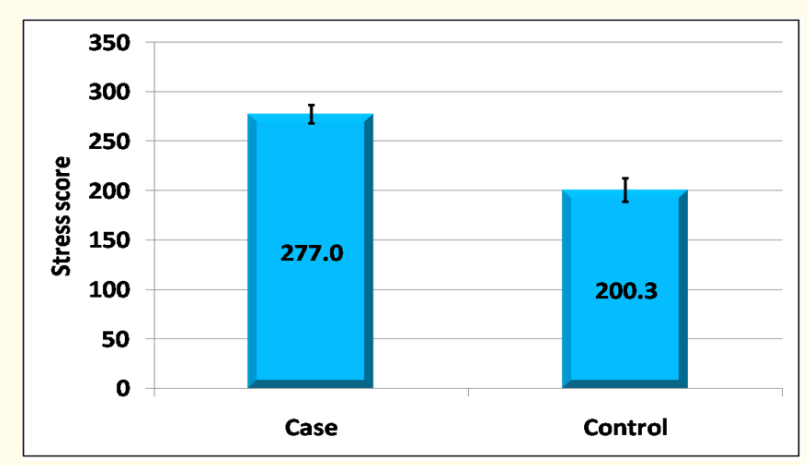

Figure 5: Comparison between case and control groups regarding stress score measure by the Social Readjustment Rating Scale.

ADHD and bipolar were the significantly more frequent psychiatric illnesses among case group. Majority of cases had psychiatric illness before addiction. 


\begin{tabular}{|c|c|c|c|c|}
\hline \multicolumn{2}{|r|}{ Variables } & $\begin{array}{c}\text { Case } \\
(\mathrm{N}=70)\end{array}$ & $\begin{array}{l}\text { Control } \\
(\mathrm{N}=35)\end{array}$ & $\mathbf{P}$ \\
\hline \multirow[t]{14}{*}{ Type } & ADHD & $13(23.6 \%)$ & $1(20 \%)$ & $0.032^{*}$ \\
\hline & Bipolar Affective & $8(14.5 \%)$ & $0(0.0 \%)$ & $0.050^{*}$ \\
\hline & Adjustment & $4(7.3 \%)$ & $0(0.0 \%)$ & 0.299 \\
\hline & Obsessive Com. & $6(10.9 \%)$ & $0(0.0 \%)$ & 0.175 \\
\hline & Panic Disorder & $5(9.1 \%)$ & $1(20 \%)$ & 0.661 \\
\hline & $\begin{array}{l}\text { Post-Traumatic } \\
\text { Stress Disorder }\end{array}$ & $5(9.1 \%)$ & $0(0.0 \%)$ & 0.167 \\
\hline & Schizoaffective & $5(9.1 \%)$ & $1(20 \%)$ & 0.661 \\
\hline & Anxiety Disorder & $5(9.1 \%)$ & $0(0.0 \%)$ & 0.167 \\
\hline & Dysthymic & $1(1.8 \%)$ & $0(0.0 \%)$ & 1.000 \\
\hline & $\begin{array}{l}\text { Chronic } \\
\text { Depression }\end{array}$ & $1(1.8 \%)$ & $1(20 \%)$ & 1.000 \\
\hline & $\begin{array}{l}\text { Cannabis } \\
\text { dependence }\end{array}$ & $1(1.8 \%)$ & $0(0.0 \%)$ & 1.000 \\
\hline & Anorexia Nervosa & $1(1.8 \%)$ & $0(0.0 \%)$ & 1.000 \\
\hline & Agoraphobia & $0(0.0 \%)$ & $1(20 \%)$ & 1.000 \\
\hline & Social Phobia & $0(0.0 \%)$ & $1(20 \%)$ & 0.333 \\
\hline \multirow{3}{*}{$\begin{array}{l}\text { Time in } \\
\text { relation } \\
\text { to abuse } \\
\text { (months) }\end{array}$} & Before abuse & $47(67.1 \%)$ & -- & -- \\
\hline & With abuse & $5(7.1 \%)$ & -- & -- \\
\hline & After abuse & $18(25.7 \%)$ & -- & -- \\
\hline
\end{tabular}

Table 5: Comparison between case and control groups regarding psychiatric illness characteristics \&Fisher Exact test.

\begin{tabular}{|c|c|c|c|c|}
\hline \multicolumn{2}{|c|}{ Variables } & $\begin{array}{c}\text { Case } \\
(\mathrm{N}=70)\end{array}$ & $\begin{array}{l}\text { Control } \\
(N=35)\end{array}$ & $\mathbf{P}$ \\
\hline \multirow[t]{2}{*}{$\begin{array}{l}\text { Duration } \\
\text { (months) }\end{array}$} & $\begin{array}{l}\text { Median } \\
\text { (IQR) }\end{array}$ & $\begin{array}{c}24.0 \\
(4.5-48.0)\end{array}$ & $\begin{array}{c}48.0 \\
(16.0-74.0)\end{array}$ & \multirow{2}{*}{$\begin{array}{c}\& \\
0.366\end{array}$} \\
\hline & Range & $0.0-120.0$ & $12.0-96.0$ & \\
\hline \multicolumn{2}{|l|}{ Episodes } & $23(41.8 \%)$ & $4(80.0 \%)$ & \#0.164 \\
\hline \multirow[t]{2}{*}{$\begin{array}{l}\text { Number of } \\
\text { episodes }\end{array}$} & $\begin{array}{c}\text { Median } \\
\text { (IQR) }\end{array}$ & $0.0(0.0-2.0)$ & $3.0(1.0-4.5)$ & \multirow{2}{*}{$\begin{array}{c}\& \\
0.034^{*}\end{array}$} \\
\hline & Range & $0.0-5.0$ & $0.0-5.0$ & \\
\hline \multirow{2}{*}{$\begin{array}{l}\text { Maximum } \\
\text { duration } \\
\text { (days) }\end{array}$} & $\begin{array}{c}\text { Median } \\
\text { (IQR) }\end{array}$ & $4.0(4.0-8.0)$ & $2.0(1.0-3.0)$ & \multirow{2}{*}{$\begin{array}{c}\& \\
<0.001^{*}\end{array}$} \\
\hline & Range & $2.0-24.0$ & $1.0-3.0$ & \\
\hline
\end{tabular}

Table 6: Comparison between case and control groups regarding psychiatric illness characteristics \&Mann Whitney test, \#Fisher Exact test, *Significant

Cases had significantly fewer numbers of episodes but its durations were significantly longer.

Citation: Areeg Osama El Shaarawy., et al. "The Relation Between Psychiatric Disorders and Substance Abuse in Adolescence and Young Adulthood". Acta Scientific Neurology 2.8 (2019): 02-25. 


\begin{tabular}{|c|c|c|c|c|c|}
\hline \multicolumn{2}{|c|}{ Variables } & $\begin{array}{c}\text { Hashish } \\
(\mathrm{N}=40)\end{array}$ & $\begin{array}{l}\text { Tram. } \\
(\mathrm{N}=14)\end{array}$ & $\begin{array}{l}\text { Both } \\
(\mathrm{N}=8)\end{array}$ & $\mathbf{P}$ \\
\hline \multicolumn{2}{|c|}{ Smoking, (n, \%) } & $34(85.0 \%)$ & $12(85.7 \%)$ & $7(87.5 \%)$ & $\# 0.983$ \\
\hline \multirow{2}{*}{$\begin{array}{c}\text { Duration } \\
\text { (Months) } \\
\text { (smokers only) }\end{array}$} & Mean \pm SD & $27.2 \pm 17.0$ & $22.8 \pm 14.8$ & $29.1 \pm 19.4$ & $\wedge$ \\
\hline & Range & $6.0-72.0$ & $6.0-48.0$ & $12.0-60.0$ & 0.674 \\
\hline \multirow{2}{*}{$\begin{array}{l}\text { Cigarettes/ day } \\
\text { (smokers only) }\end{array}$} & Mean \pm SD & $18.8 \pm 8.9$ & $16.3 \pm 8.8$ & $15.7 \pm 11.7$ & $\wedge$ \\
\hline & Range & $5.0-40.0$ & $5.0-40.0$ & $5.0-40.0$ & 0.578 \\
\hline \multicolumn{2}{|c|}{ History of medical condition } & $2(5.0 \%)$ & $1(7.1 \%)$ & $0(0.0 \%)$ & $\begin{array}{c}\# \\
0.752\end{array}$ \\
\hline \multicolumn{2}{|c|}{ Family history of substance abuse, (n, \%) } & $19(47.5 \%)$ & $5(35.7 \%)$ & $4(50.0 \%)$ & $\begin{array}{c}\# \\
0.716\end{array}$ \\
\hline \multicolumn{2}{|c|}{ Family history of psychiatric illness (n, \%) } & $15(37.5 \%)$ & $4(28.6 \%)$ & $1(12.5 \%)$ & $\begin{array}{c}\# \\
0.364\end{array}$ \\
\hline
\end{tabular}

Table 8: Comparison between Hashish, tramadol and both regarding Family history of substance abuse\& psychiatric illness and smoking.

${ }^{\wedge}$ ANOVA test, \#Chi square test, *Significant

\begin{tabular}{|c|c|c|c|c|c|}
\hline \multicolumn{2}{|l|}{ Variables } & $\begin{array}{c}\text { Hashish } \\
(\mathrm{N}=40)\end{array}$ & $\begin{array}{l}\text { Tram. } \\
(\mathrm{N}=14)\end{array}$ & $\begin{array}{l}\text { Both } \\
(\mathrm{N}=8)\end{array}$ & $\mathbf{P}$ \\
\hline \multirow[t]{2}{*}{ Addiction duration (months) } & Mean \pm SD & $16.8 \pm 12.1$ & $21.4 \pm 9.3$ & $21.0 \pm 15.0$ & \multirow{2}{*}{$\stackrel{\wedge}{0.371}$} \\
\hline & Range & $2.0-60.0$ & $6.0-36.0$ & $6.0-48.0$ & \\
\hline \multirow[t]{2}{*}{ Hashish usual dose/day } & Mean \pm SD & $2.4 \pm 1.1$ & -- & $2.1 \pm 1.1$ & \multirow{2}{*}{$\begin{array}{c}\# \\
0.613\end{array}$} \\
\hline & Range & $1.0-5.0$ & -- & $1.0-4.0$ & \\
\hline \multirow[t]{2}{*}{ Hashish maximum dose/day } & Mean \pm SD & $6.4 \pm 3.1$ & -- & $5.9 \pm 3.2$ & \multirow{2}{*}{$\begin{array}{c}\# \\
0.698\end{array}$} \\
\hline & Range & $3.0-20.0$ & -- & $2.0-10.0$ & \\
\hline \multirow[t]{2}{*}{ Tramadol usual dose/day } & Mean \pm SD & -- & $2.9 \pm 1.4$ & $2.6 \pm 1.3$ & \multirow{2}{*}{$\begin{array}{c}\# \\
0.699\end{array}$} \\
\hline & Range & -- & $1.0-5.0$ & $1.0-5.0$ & \\
\hline \multirow{2}{*}{$\begin{array}{l}6.4 \pm 2.4 \\
3.0-10.0\end{array}$} & Mean \pm SD & -- & & $6.4 \pm 3.2$ & \multirow{2}{*}{$\begin{array}{c}\# \\
0.988\end{array}$} \\
\hline & Range & -- & & $2.0-10.0$ & \\
\hline
\end{tabular}

Table 9: Comparison between Hashish, tramadol and both regarding substance abuse duration and dose.

${ }^{\wedge}$ Independent t-test, \#ANOVA test, *Significant

\begin{tabular}{|l|l|c|c|c|c|}
\hline \multicolumn{2}{|c|}{ Variables } & $\begin{array}{c}\text { Hashish } \\
(\mathbf{N = 4 0 )}\end{array}$ & $\begin{array}{c}\text { Tram. } \\
(\mathbf{N = 1 4 )}\end{array}$ & $\begin{array}{c}\text { Both } \\
(\mathbf{N = 8 )}\end{array}$ & \multirow{2}{*}{ P } \\
\cline { 1 - 5 } Presence of Psychiatric illness & Before & $32(80.0 \%)$ & $10(71.4 \%)$ & $6(75.0 \%)$ & \multirow{2}{*}{0.670} \\
\cline { 2 - 6 } & After & $8(20.0 \%)$ & $4(28.6 \%)$ & $2(25.0 \%)$ & \\
\hline \multirow{2}{*}{ Stress test } & Mean \pm SD & $265.0 \pm 74.9$ & $258.5 \pm 85.3$ & $314.5 \pm 61.3$ & \multirow{2}{*}{0.205} \\
\cline { 2 - 6 } & Range & $76.0-400.0$ & $76.0-372.0$ & $219.0-372$ & \\
\hline
\end{tabular}

Table 10: Comparison between Hashish, tramadol and both regarding psychiatric condition.

^ANOVA test, `\#Fisher Exact test0, `*Significant 
The Relation Between Psychiatric Disorders and Substance Abuse in Adolescence and Young Adulthood

\begin{tabular}{|l|c|c|c|c|}
\hline \multicolumn{1}{|c|}{ Variables } & $\begin{array}{c}\text { Hashish } \\
\text { (N=40) }\end{array}$ & $\begin{array}{c}\text { Tram. } \\
\mathbf{( N = 1 4 )}\end{array}$ & $\begin{array}{c}\text { Both } \\
\mathbf{( N = 8 )}\end{array}$ & \#P \\
\hline ADHD & $9(28.1 \%)$ & $3(30.0 \%)$ & $0(0.0 \%)$ & 0.457 \\
\hline Bipolar Affective Disorder & $3(9.4 \%)$ & $2(20.0 \%)$ & $2(33.3 \%)$ & 0.222 \\
\hline Adjustment Disorder & $2(6.3 \%)$ & $0(0.0 \%)$ & $1(16.7 \%)$ & 0.450 \\
\hline Obsessive Compulsive Disorder & $4(12.5 \%)$ & $0(0.0 \%)$ & $1(16.7 \%)$ & 0.492 \\
\hline Panic Disorder & $3(9.4 \%)$ & $2(20.0 \%)$ & $0(0.0 \%)$ & 0.631 \\
\hline Post-Traumatic Stress Disorder & $3(9.4 \%)$ & $2(20.0 \%)$ & $0(0.0 \%)$ & 0.631 \\
\hline Schizoaffective Disorder & $1(3.1 \%)$ & $0(0.0 \%)$ & $2(33.3 \%)$ & 0.070 \\
\hline Anxiety Disorder & $4(12.5 \%)$ & $0(0.0 \%)$ & $0(0.0 \%)$ & 0.752 \\
\hline Dysthymic Disorder & $1(3.1 \%)$ & $0(0.0 \%)$ & $0(0.0 \%)$ & 1.000 \\
\hline Chronic Depression & $0(0.0 \%)$ & $1(10.0 \%)$ & $0(0.0 \%)$ & 0.355 \\
\hline Cannabis Dependence & $1(3.1 \%)$ & $0(0.0 \%)$ & $0(0.0 \%)$ & 1.000 \\
\hline Anorexia Nervosa & $1(3.1 \%)$ & $0(0.0 \%)$ & $0(0.0 \%)$ & 1.000 \\
\hline Agoraphobia & $9(28.1 \%)$ & $3(30.0 \%)$ & $0(0.0 \%)$ & 1.000 \\
\hline
\end{tabular}

Table 11: Comparison between Hashish, tramadol and both regarding psychiatric illness types. \#Fisher Exact test.

\begin{tabular}{|c|c|c|c|c|c|}
\hline \multicolumn{2}{|l|}{ Variables } & $\begin{array}{c}\text { Hashish } \\
(\mathrm{N}=40)\end{array}$ & $\begin{array}{c}\text { Tram. } \\
(\mathrm{N}=14)\end{array}$ & $\begin{array}{l}\text { Both } \\
(\mathrm{N}=8)\end{array}$ & $\mathbf{P}$ \\
\hline \multirow{3}{*}{$\begin{array}{l}\text { Time in relation to abuse } \\
\text { (months) }\end{array}$} & Before & $29(72.5 \%)$ & $9(64.3 \%)$ & $5(62.5 \%)$ & \multirow{3}{*}{$\begin{array}{c}\# \\
0.600\end{array}$} \\
\hline & With & $3(7.5 \%)$ & $0(0.0 \%)$ & $0(0.0 \%)$ & \\
\hline & After & $8(20.0 \%)$ & $5(35.7 \%)$ & $3(37.5 \%)$ & \\
\hline \multirow[t]{2}{*}{ Duration (months) } & Median (IQR) & $\begin{array}{c}24.0 \\
(11.3-57.0)\end{array}$ & $\begin{array}{c}27.0 \\
(0.0-63.0)\end{array}$ & $\begin{array}{c}28.0 \\
(0.5-48.0)\end{array}$ & \multirow{2}{*}{$\begin{array}{c}\& \\
0.720\end{array}$} \\
\hline & Range & $0.0-120.0$ & $0.0-120.0$ & $0.0-50.0$ & \\
\hline \multicolumn{2}{|l|}{ Episodes } & $10(31.3 \%)$ & $5(50.0 \%)$ & $4(66.7 \%)$ & \#0.191 \\
\hline \multirow[t]{2}{*}{ Number of episodes } & Median (IQR) & $\begin{array}{c}0.0 \\
(0.0-1.0)\end{array}$ & $\begin{array}{c}0.5 \\
(0.0-2.0)\end{array}$ & $\begin{array}{c}2.5 \\
(0.0-3.0)\end{array}$ & \multirow{2}{*}{$\begin{array}{c}\& \\
0.268\end{array}$} \\
\hline & Range & $0.0-5.0$ & $0.0-4.0$ & $0.0-3.0$ & \\
\hline \multirow[t]{2}{*}{ Maximum duration of episodes } & Median (IQR) & $\begin{array}{c}8.0 \\
(3.8-8.0)\end{array}$ & $\begin{array}{c}4.0 \\
(3.5-8.0)\end{array}$ & $\begin{array}{c}4.5 \\
(4.0-19.3)\end{array}$ & \multirow{2}{*}{$\begin{array}{c}\& \\
0.557\end{array}$} \\
\hline & Range & $2.0-20.0$ & $3.0-8.0$ & $4.0-24.0$ & \\
\hline \multirow[t]{2}{*}{ Stress test } & Mean \pm SD & $265.0 \pm 74.9$ & $258.5 \pm 85.3$ & $314.5 \pm 61.3$ & \multirow{2}{*}{$\wedge 0.205$} \\
\hline & Range & $76.0-400.0$ & $76.0-372.0$ & $219.0-372$ & \\
\hline
\end{tabular}

Table 12: Comparison between Hashish, tramadol and both regarding psychiatric illness characteristics.

${ }^{\wedge}$ ANOVA test, \& Kruskal Walis test, \#Fisher Exact test, *Significant

\section{Discussion}

Drug use is a huge problem in the modern world, with people's lives being lost and their productivity declining dramatically. In 2012, there was an estimated 183,000 deaths reported due to drug use. According to the National Addiction survey, there are at least 500,000 addicts in Cairo alone and these are just the ones who have requested medical treatment. Substance use poses a great burden on the economy as these substance abusers are usually not-working and hence do not support the economy in any way; as well as the fact that most of them resort to stealing and committing other crimes to pay for these substances that they abuse. Substance abusing costs the Egyptian economy approximately $\$ 800$ million 
per year, which includes the money the government pays to try to eradicate the problem.

Individuals with severe mental illness bear an enormous burden owing to smoking, alcohol and drugs. In the sample of 70 people that we have studied, we found that substance abuse among individuals with severe psychiatric disorders to be markedly higher than in population control individuals. This association extends across substances (hash, tramadol and alcohol), and across psychiatric diagnosis (e.g. depression, bipolar disorder and schizophrenia, etc.)

Substance use disorders have a serious impact on adolescents because these disorders have high prevalence rates and frequent associations with psychiatric disorders. Adolescents with substance use disorders tend to have higher rates of co-morbid psychiatric disorders and are more likely to report a history of trauma and physical and/ or sexual abuse than adolescents without a substance use disorder. In addition, psychiatric disorders in adolescents often predate the substance use disorder. Once the substance use disorder develops, the psychiatric disorder may be further exacerbated [1]

Although substance abuse among individuals with psychiatric disorders has been documented [33], this study showed that there is a continuing pressing need to target smoking, alcohol and tramadol use among individuals with mental illness.

In our study we conducted a cross sectional comparative study among 70 patients who are diagnosed with substance abuse disorder according to DSM IV within the age range of 15 years until 21 years of age, who sought treatment at the addiction clinic at the Institute of Psychiatry of Ain Shams University hospitals, over a period of 12 months. Exclusion criteria were intoxication, unconsciousness and mental retardation.

Eligible subjects below 18 years of age were assessed by the Mini International Neuropsychiatric Interview for Children and Adolescents for diagnosing psychiatric comorbidity, while those above 18 years were assessed by the Structured Clinical interview for DSM-IV. Stressful life events were assessed by the Social Readjustment Rating Scale for the young; while the social class of the patients was determined using the Fahmy and Sherbini's Social Classification Scale. Moreover, the subjects were investigated about their age, marital status, home dynamics, employment and education level.

\section{Demographic Characteristics of our study group}

Our study showed that the mean age of our study was 18 years, which is inconsistent with (Hamdi., et al. 2011) that found that substance abuse is most common at age 20 and above. This signifies that the age at which adolescents start abusing substance, is decreasing rapidly and they are now starting Substance use disorder (SUD) at an earlier age.

The gender of the patients in our study group were all males, compared to $2 \%$ females and $98 \%$ males in (Khalil., et al. 2008). This signifies that a lot more males seem to seek help for SUD than females in our community. According to [19], the ratio of females in Cairo who are substance abusers is thought to be much higher, however, this could be due to cultural boundaries and limitations, as many females feel extremely horrified by the thought of seeking help for their substance abusing problems, as substance abuse is regarded more of a moral issue than a disease that needs help. Add to that the fact that substance abuse in the adolescent period is much more common amongst males than females.

We need to assess the barriers and limitations that keep females from seeking professional help in today's modern age.

Most of the patients in our study are from a very low social class, with inadequate incomes which is in accordance with the findings in [25]. This could be due to the fact that the majority of patients who present to university public hospitals are from a lower social class, as opposed to people from a higher social class who seek help at private hospitals and private clinics.

Only two percent $(2 \%)$ of the patients in our sample were married and that is obviously because of the adolescent age group we were dealing with as they are all too young to be married. These results are consistent with $[2,12,25]$ who have also shown that most of the patients in their sample were single. That is because in Egypt, most males marry after the age of 25, i.e. after finishing their college education or after establishing themselves financially to be able to support a wife and children.

Our study showed that (68.6\%) of the patients are working, while (31.4\%) are not. This indicates that SU causes impairment and the patients cannot work regularly and hence they become unemployed.

\section{Smoking and family history}

In our study group, we found that $(87.1 \%)$ of the patients are smokers, as opposed to only (28.6\%) of the control group who 
actually smoke. These results further prove the fact that smoking is the gateway to all drug use and Substance abuse in the world. Tobacco smoking often starts during adolescence but can have important health effects throughout life. Because of nicotine dependence and social factors, initiation of smoking during adolescence is closely associated with persistent smoking in adulthood and with the many adverse health effects associated with chronic smoking. Cigarette smoking is the leading preventable cause of mortality, responsible for nearly six million deaths worldwide and if present trends continue, this toll is projected to rise to over eight million deaths per year by 2030, according to reports by the (WHO, 2011). Therefore, in order to successfully eradicate the SUD problem, we must also address smoking as a huge problem and as the stepping stone to SUD, as it's the first step. We need to endorse our anti-smoking campaigns and help raise more awareness amongst our peers, our family members and our community. Our study is further proof of the crisis we have, that people who tend to smoke usually start in their adolescence period and continue for the rest of their lives, unless they decide to quit at some point.

(47.1\%) of the patients exhibited a positive family history of substance abuse, hence indicating the role of families in the choices being made by the patients or rather the lives that they are forced into. That is further supported by (Ng., et al. 2002) who hypothesized that family members in the Pacific, American and Asian populations could hinder treatment as many of them accept SUD as a normality and hence do not see the point in seeking treatment. According to [15] many people in some cultures saw seeking help for SUD as inconsistent with the cultural beliefs to maintain a harmonious appearance within the family.

In the same way, (32.9\%) of the patients showed a positive family history of psychiatric illnesses, as opposed to negative family history in the control group; this finding further proves the genetic theories supporting psychiatric illnesses as researchers learned that genes influence how these disorders manifest and that they tend to aggregate in families as proven by [29]. This emphasizes that the best ways to manage psychiatric disorders is via obtaining a detailed family history and providing group family therapies for the whole family, to ensure everyone knows how to deal with the disorders, because sometimes family members do not admit to suffering from mental disorders and hence, their suffering may be overlooked.
Substance abuse

In our study, Hashish was the most commonly abused drug (57.1\%), with Tramadol coming in second place $(20.0 \%)$ and finally alcohol at (5.7\%). This was also the case with (Hamdi., et al. 2011 and Okasha., et al. 1985), who have proven that Hashish was the most commonly used substance in the Egyptian community. That could be due to the fact that Hashish is more culturally acceptable in the community, believing that it's not an addictive substance and that it has no detrimental effects on people's health.

As we can observe, tramadol seems to be a growing problem amongst substance users in today's world as supported by (Fawzi, 2011); and that could be attributed to the fact that it became available in the streets lately in the past few years. As well as that, many people take it either to mask physical pain, e.g. after a major surgery etc., or to help them stay awake for longer hours and hence work for a longer duration, which then enables them to bring home a higher income, since most of them live in very low social statuses.

Alcohol on the other hand, is the least abused substance, due to the belief that most Egyptians have that it's a religious taboo and hence unacceptable to be seen drinking it. However, in the very low social classes, it's occasionally served in big celebrations like weddings etc.

These results do not match (Benishek., et al. 1998)'s study which was conducted on 909 clients receiving SUD treatment, where the percentage of alcohol abuse was (30\%); and that difference is owing to cultural differences and the fact that alcohol is culturally acceptable in the western world.

\section{Psychiatric condition and stress score}

In our study group, (78.6\%) of the case group exhibited features of psychiatric illness; proving how substance abuse carries a strong co-morbidity with psychiatric illnesses. This is consistent with the results of the Methods for the Epidemiology of Child and Adolescent Mental Disorders study, (Kandel., et al. 1999), which revealed higher rates of psychiatric disorders among adolescents with current substance use disorders than amongst those without substance use disorders. Of the 401 adolescents enrolled in this study, 25 (6.2\%) had a SUD diagnosis; Our study found that there is an association between psychiatric disorders and SUD however the study design cannot clarify whether the SUD causes development of psychiatric disorders or that psychiatric disorders predispose to SUD. 
One of the aims of our study was to assess the role of stress on substance abuse in adolescents and young adults. There was a significant difference between the cases and control groups regarding the stress scores; as the mean stress score by the case group was (277.0), which is a score indicating severe stress, while the control group had a mean stress score of (200.0); thus, indicating that stress is one of the major factors that forces adolescents to become substance abusers; as they are unable to cope with their major problems on their own. These stresses were major, for instance, most of the patients come from homes that were affected by divorced of their parents with parental fights over custody of the children. Many patients on the other hand, suffered the death of a parent, with the other parent working day and night to provide a stable adequate income for the family. (34.3\%) of the patients were illiterate and hence being robbed of their right to receive a good education is one of the main reasons behind their high stress scores.

\section{Psychiatric Illnesses among case group}

In our study group, ADHD was the most common psychiatric disorder with a frequency of (23.6\%), followed by BAD (14.5\%), then OCD (10.9\%) and PTSD (9.1\%) along with Schizoaffective Disorder at (9.1\%). Anxiety disorder is present in (9.1\%), along with Panic Disorder in (9.1\%). These results are different from the ones obtained by (Rao., et al. 1999), where depression was the biggest problem among Substance abuser adolescents, where up to $35 \%$ of depressed adolescents developed SUD. SUDs comorbid with depression contribute to increased rates of adolescent suicide. Furthermore, adolescents who attempt suicide are more likely to have the psychosocial stressors of recent familial separation and a history of family dysfunction and a quarrelsome home atmosphere.

Another study made by (Deas-Nesmith., et al. 1998) has found out that anxiety disorders commonly co-exist with SUDs amongst adolescents, and these anxiety symptoms usually precede the onset of substance use in adolescents by approximately 2 years. Of 90 studied adolescents from 3 different in-patient treatment facilities, 40 adolescents (44\%) had both anxiety and SUDs. This has been attributed to the fact that adolescents with anxiety disorders may use substances to self-medicate the anxiety symptoms or the affective disorder symptoms.

Wilens., et al. (2004) has proven that adolescents with SUD are more likely to have BAD than adolescents without SUD. Risk factors associated with having comorbid substance use and BAD include early age at onset for BAD, male gender, positive family history of SUD, as well as the presence of mania, as evidenced by (Tohen., et al. 1998).

ADHD is a frequent association with SUD, but whether ADHD itself predisposes an individual to substance use or whether being treated for medications for ADHD predisposes individuals to SUD, is a question that continues to be explored by researchers. A study of alcohol and drug use disorders by (Biederman., et al. 1997) found that adolescents with and without ADHD developed SUD at the same rate, suggesting that ADHD alone doesn't predispose to SUD. However, the same study found that SUD was predicted by the presence of conduct disorder and BAD. (Wilens., et al. 2003), on the other hand, concluded that a child with ADHD who was untreated or under-medicated was more likely to abuse substances, which emphasizes the importance to treat patients with ADHD to full remission.

In our study, chronic depression constituted only (1.8\%), while dysthymic disorder made up (1.8\%), and finally with anorexia nervosa making up (1.8\%).

Due to people's lack of knowledge about psychiatric problems, and due to the stigma surrounding mental health issues, many young people with psychiatric illnesses suffer in silence; their families do not seek professional help, and that is why many of these children by the time they reach adolescence, start to resort to drugs in order to mask or ease their psychological pain.

\section{Summary and Conclusions}

Data of Substance abuse gathered from all over the world, has indicated that Substance use and dependence cause a significant burden on societies and individuals across the globe. The World Health Report 2002 indicated that $8.9 \%$ of the total burden of disease comes from the use of psychoactive substances (WHO, 2004). In 2005, the WHO reported that there are about 200 million addicts around the world.

\section{Subjects and methods}

In our study, we conducted a cross-sectional study among 70 patients who are diagnosed with substance use disorder according to DSM IV between the ages of 15 and 21, who presented to the Substance treatment program at the Institute of Psychiatry of Ain Shams University hospitals over a period of 12 months. 
Exclusion criteria were limited mental competency, intoxication, presence of a serious medical condition or the inability or refusal to provide an informed written consent.

We also interviewed 35 people (the control group), who were free from substance use disorder, yet were relatives of the patients (cases) who participated in the study. They also had to provide a written consent and they had to abide by the same exclusion criteria as the cases.

All subjects involved in the study were assessed using

1. Mini International Neuropsychiatric Interview for Children and Adolescent (MINI-KID) for patients below 18 years of age (Sheehan., et al. 1990).

2. Structured Clinical Interview for DSM-IV Axis I Disorder (SCID-I) for patients above 18 years of age [14].

3. Fahmy and Sherbini's Social Classification Scale, which is used to determine the social class of the patient.

4. Social Readjustment Rating Scale for Young (SRRS-Y) (Holmes., et al. 1967).

The main findings of this study were

Regarding sociodemographic characteristics

They were $100 \%$ male. The mean age of our study was 18 years of age, and the majority of our patients were single (98\%). Most of our patients are from a very low social class, with inadequate incomes.

Regarding smoking and family history

In our study group, we found that $87.1 \%$ of the patients are smokers.

We also found out that $47.1 \%$ of the patients exhibited a positive family history of substance abuse and in the same way, $32.9 \%$ of the patients showed a positive family history of psychiatric illnesses.

\section{Regarding substance abuse}

In our study, Hashish was the most commonly abused forming a percentage of $57.1 \%$ of the cases, while Tramadol came in second place with $20.0 \%$ and finally alcohol formed $5.7 \%$.

\section{Regarding psychiatric condition and stress score}

In our study, $78.6 \%$ of the case group exhibited features of psychiatric illness; we also found out that the mean stress score by the case group was 277.0.

\section{Regarding psychiatric illnesses}

In our study, ADHD was the most common psychiatric disorder, with a frequency of $23.6 \%$, followed by Bipolar Affective Disorder (BAD) at $14.5 \%$, then Obsessive Compulsive Disorder (OCD) at $10.9 \%$. We also have Post-traumatic Stress Disorder at 9.1\% along with Schizoaffective Disorder at $9.1 \%$. Anxiety disorders is present in $9.1 \%$, along with panic disorder in $9.1 \%$.

Since our study was implemented in Egypt (an Arab country), the epidemiological data on drug abuse (including alcohol) is still very little; and minimal official reports can be obtained as drug abuse is prohibited by legal and religious systems.

With a population of around 80 million inhabitants, drug addiction is considered one of the serious problems that worry both the people and the government. It affects young people within their productive years and may lead to many problems such as social maladaptation, decreased work productivity and job loss.

As can be further proven by our study, stress has long been recognized as one of the most powerful triggers for drug abuse, craving and relapse. People who experience major trauma and those with PTSD or depression may self-medicate with drugs or alcohol to relax and cope with stress (Williams, 2002).

Stress exists in various forms in our lives; it could be in the form of parents' divorcing, money troubles, dropping out of school, etc.. In today's modern age, it's extremely difficult to remain resilient with all the distress that surrounds us. Therefore, people who face strong stressors in their lives, often do resort to substance use to mask the pain of everything they are going through. That's why adolescence is a very critical stage, as teens are extremely vulnerable to peer pressure, often leading to substance abuse.

As can be clearly seen from our results, substance abuse in adolescents is a grave problem with direct consequences that affects a marked percentage of adolescents nowadays. Psychiatric disorders could present as risk factors for substance abuse; hence, management of these comorbid psychiatric disorders may prevent the persistence of this problem into adulthood.

To sum up, substance use remains a public health problem among adolescents. Comorbidity is the rule rather than the exception, and psychiatric disorders often predate SUD. However, treatment can alleviate impairment caused by comorbid psychiatric and SUDs. The earlier we initiate the treatment of these adolescents, the better the outcome. The longer the time an adolescent spends in treatment, the better the prognosis. 


\section{Recommendations}

Clinical Recommendations

- We need to ensure that every Substance use disorder (SUD) adolescent patient gets a thorough, extensive full clinical examination, where his/her mental health status is also assessed to make sure we manage any underlying psychiatric disorders effectively, which in turn would improve the prognosis of the SUDs.

- Psychoeducation of the families about the nature of SUDs, aiming at fighting the stigma surrounding addiction and explaining more how it's more of a disease and less of a crime, to enable the patients to gain more acceptance into society and be able to adhere better to treatment plans.

- Establish programs that aim at the prevention of Substance Use Disorders, especially in schools and bigger communities like the sports clubs and neighborhoods etc..

- Create more awareness programs that aim at eradicating the ignorance and the stigma surrounding mental health and SUDs, encouraging people to seek professional help when and if needed.

\section{Research Recommendations}

- A larger-sized sample may be needed to confirm our results and to re-examine other associations.

- Follow-up studies aiming at evaluation of the SUDs after managing the patient's co-morbid psychiatric disorders.

- $\quad$ Additional studies are needed to help clarify the role that stigma and "saving face" play in the initiation of substance use and voluntarily seeking substance abuse treatment.

\section{Limitations}

Concerning the limitations, our study was limited by:

1. The study was limited to patients of Ain-Shams University hospitals, the institute of psychiatry and not including those in other hospitals of the ministry of health or other modalities of addiction services and hence the results couldn't be generalized.

2. Due to cultural fears, no female patients have participated in this study, as most female patients are unable to face society and seek treatment for their SUDs; as many societies in Egypt consider that to be an even worse disaster than the males having a SUD.

3. The study did not clarify the relation between psychiatric disorders and substance use disorders as to which causes the other, because of the study design (cross sectional), hence, follow up studies are required to clarify the causality.

4. Some patients at the SUD clinic, refused to participate in the study, for fear of public shame or that their confidentiality may be breached.

\section{Bibliography}

1. Psychiatric Association. Diagnostic and Statistical Manual of Mental Disorders, 4th, text revision, American Psychiatric Association, Washington, DC (2013).

2. Amr M., et al. "Substance abuse and dependence among patients attending an emergency hospital in Eastern Nile Delta, Egypt". Journal of Psychiatry 17 (2014): 532-537.

3. Amr M., et al. "Updated version of Fahmy and Sherbini's Social Classification Scale. (2012).

4. Arnold. "Modern Perspectives in Psychosocial Pathology". Journal of Psychiatry 146(1989): :1131-1141.

5. Brown T., et al. "Equity impact of European individual-level smoking cessation interventions to reduce smoking in adults: a systematic review". European Journal of Public Health 24.4 (2014): 551.

6. Buckley PF. "Prevalence and consequences of the dual diagnosis of substance abuse and severe mental illness". Journal of Clinical Psychiatry 67.7 (2006): 5.

7. Buckley PF. "Prevalence and consequences of the dual diagnosis of substance abuse and severe mental illness". Journal of Clinical Psychiatry 67.7 (2006): 5.

8. Chapman S., et al. "Citation bias in reported smoking prevalence in people with schizophrenia". Australian and New Zealand Journal of Psychiatry 43.3 (2009): 277-282.

9. $\quad$ Deas. Journal of Clinical Psychiatry 67.7 (2006): 18-23.

10. Dubertret C., et al. "Lifetime positive symptoms in patients with schizophrenia and cannabis abuse are partially explained by co-morbid addiction". Schizophrenia Research 86.1-3 (2006): 284-290. 
11. El-Akabawi AS. Drug Abuse in the Arab World: a country profile Egypt: in Okasha A. Maj M. (eds) Images in psychiatry: An Arab perspective (2001): 143-150.

12. El-Sawy H., et al. "Gender differences in risks and pattern of drug abuse in Egypt". Egyptian Journal of Neurology, Psychiatry and Neurosurgery 47 (2010): 413-418.

13. Feng Y., et al. "Convergence and divergence in the etiology of myelin impairment in psychiatric disorders and drug addiction". Neurochemical Research 33.10 (2008): 1940-1949.

14. First MB., et al. Structured Clinical Interview for DSM-IV Axis I Disorders (SCID-I) in Handbook of Psychiatric Measures, Washington, DC, American Psychiatric Association (1995).

15. Fong TW and Tsuang J. "Asian-Americans addictions and barriers to treatment". Psychiatry 4.11 (2007): 51-59.

16. Fryers T., et al. "The distribution of the common mental disorders: social inequalities in Europe". Clinical Practical Epidemiological Mental Health 1 (2005): 14.

17. Ghanem MH., et al. "MINI-International Neuropsychiatric Interview". Translation and validity study. M.D. Thesis, Ain Shams University, Egypt (2000).

18. Grant BF., et al. "Epidemiology of DSM-5 Alcohol Use Disorder: Results From the National Epidemiologic Survey on Alcohol and Related Conditions III". Journal of the American Medical Association Psychiatry 72.8 (2015): 757-766.

19. Hamdi E., et al. "The national addiction survery - final report". Research unit of general secretariat of mental health, ministry of health, Egypt (2011).

20. Hartz SM., et al. "Comorbidity of severe psychotic disorders with measures of substance use". Journal of the American Medical Association Psychiatry 71.3 (2014): 248-254.

21. Holmes TH and Rahe RH. "The social Readjustment Rating Scale". Journal of Pschychosomatic Research 11.2 (1967): 213-218.

22. Joffe A and Yancy WS. American Academy of Pediatrics Committee on Substance Abuse, American Academy of Pediatrics Committee on Adolescence. "Legalization of marijuana: potential impact on youth". Pediatrics 113.6 (2004): e632-e638.
23. Kashani JH., et al. "Double depression in adolescent substance abusers". Journal of Affective Disorders 8.2 (1985): 153-157.

24. Kendler KS., et al. "Lifetime prevalence, demographic risk factors, and diagnostic validity of nonaffective psychosis as assessed in a US community sample. The National Comorbidity Survey". Archives of General Psychiatry 53.11 (1996): 10221031.

25. Khalil A., et al. "Characterization of Substance Abuse Patients Presenting for Treatment at a University Psychiatric Hospital in Cairo". Egypt Addictive Disorders and Their Treatment 7.4 (2008): 199-209.

26. Kilmer B. "Policy designs for cannabis legalization: starting with the eight Ps". The American Journal of Drug and Alcohol Abuse 40.4 (2014): 259-261.

27. Kivimies K., et al. "Opioid abuse and hospitalization rates in patients with schizophrenia". Nordic Journal of Psychiatry 70.2 (2016): 128-132.

28. Koskinen J., et al "Rate of cannabis use disorders in clinical samples of patients with schizophrenia: a meta-analysis". Schizophrenia Bull 36.6 (2010): 1115-1130.

29. Maier and Wolfgang. "Psychiatric genetics: overview on achievements, problems, perspectives". In Leboyer, M, Bellivier, F. Psychiatric genetics: methods and reviews Humana Press (2003): 1-20.

30. Marieczurrena R. "Recovery from addiction without treatment: an interview study". Scandinavian Journal of Behaviour Therapy 25 (1996): 57.

31. Merline AC., et al. "Substance use among adults 35 years of age: prevalence, adulthood predictors, and impact of adolescent (2004).

32. Moore BA., et al. "Computer-based interventions for drug use disorders: A systematic review". Journal of Substance Abuse Treatment 40.3 (2011): 215-223.

33. Moore E., et al. "The impact of alcohol and illicit drugs on people with psychosis: the second Australian National Survey of Psychosis". Australian and New Zealand Journal of Psychiatry 46.9 (2012): 864-878.

34. Naegle MA., et al. "Alcohol and substance abuse". Western Journal of Medicine 176 (2002): 259-263. 
35. Okasha A. "History of mental health in the arab world". In images in Psychiatry: An Arab perspective (eds A. Okasha \& M. Maj) 1- 20 World psychiatric association (2011).

36. Power RA., et al. "Genetic predisposition to schizophrenia associated with increased use of cannabis". Molecular Psychiatry 19.11 (2014): 1201-1204.

37. Soueif MI., et al. "The Extent of Nonmedical Use of Psychoactive Substances Among Secondary School Students in Greater Cairo". Drug and Alcohol Dependence 9.1 (1982): 15-41.

38. Soueif MI., et al. "The use of psychoactive substances by female Egyptian university students, compared with their male colleagues on selected ITEMS". Drug and Alcohol Dependence 19.3 (1987): 233-247.

39. Swartz MS., et al. "Substance use and psychosocial functioning in schizophrenia among new enrollees in the NIMH CATIE study". Psychiatry Services 57.8 (2006): 1110-1116.

40. Thoma P and Daum I. "Comorbid substance use disorder in schizophrenia: a selective overview of neurobiological and cognitive underpinnings". Psychiatry Clinical Neuroscience 67.6 (2013): 367-383.

41. Tsai J and Rosenheck RA. "Psychiatric comorbidity among adults with schizophrenia: a latent class analysis". Psychiatry Research 210.1 (2013):16-20.

42. United Nations Office on Drugs and Crime (2011).

43. United Nations Office on Drugs and Crime Vienna, World Drug Report.

44. Wang GS., et al. "Pediatric marijuana exposures in a medical marijuana state”. Journal of the American Medical Association Pediatrics 167.7 (2013): 630-633.

45. Weissman MM., et al. "Children of de- pressed parents Increased psychopathology and early onset of major depression". Archives of General Psychiatry 44.10 (1987): 847-853.

46. Westermeyer J. "Comorbid schizophrenia and substance abuse: a review of epidemiology and course". The American Journal on Addictions 15.5 (2006): 345-355.

47. World Health Organization "Lexicon of Alcohol and Drug Terms". Geneva (1994).
48. World Health Organization Report on the Global Tobacco Epidemic. Warning about the dangers of tobacco. World Health Organization, Geneva (2011).

49. Wunsch MJ and Weaver MF. "Alcohol and other drug use during pregnancy: Management of the affected mother and child". In: Principles of Addiction Medicine, 4th edition, Ries R, Fiellin D, Miller S, Saitz R. (Eds), American Society of Addiction Medicine, Inc., Chevy Chase, MD (2009): 1111.

50. Ziedonis D., et al. "Serious mental illness and tobacco addiction: a model program to address this common but neglected issue". The American Journal of the Medical Sciences 326.4 (2003): 223-230.

Volume 2 Issue 8 August 2019

(C) All rights are reserved by Areeg Osama El Shaarawy. et al. 